Review Article

\title{
Insights on Localized and Systemic Delivery of Redox-Based Therapeutics
}

\author{
Nicholas E. Buglak $\mathbb{D}^{1,2,3}$ Elena V. Batrakova, ${ }^{2,4}$ Roberto Mota, ${ }^{1,2}$ \\ and Edward S. M. Bahnson iD ${ }^{1,2,3,5}$ \\ ${ }^{1}$ Department of Surgery, Division of Vascular Surgery, University of North Carolina at Chapel Hill, Chapel Hill, NC 27599, USA \\ ${ }^{2}$ Center for Nanotechnology in Drug Delivery, University of North Carolina at Chapel Hill, Chapel Hill, NC 27599, USA \\ ${ }^{3}$ Curriculum in Toxicology, University of North Carolina at Chapel Hill, Chapel Hill, NC 27599, USA \\ ${ }^{4}$ Division of Pharmacoengineering and Molecular Pharmaceutics, University of North Carolina at Chapel Hill, Chapel Hill, \\ NC 27599, USA \\ ${ }^{5}$ Department of Cell Biology \& Physiology, University of North Carolina at Chapel Hill, Chapel Hill, NC 27599, USA
}

Correspondence should be addressed to Edward S. M. Bahnson; edward_bahnson@med.unc.edu

Received 30 October 2017; Accepted 18 December 2017; Published 14 February 2018

Academic Editor: Maria C. Franco

Copyright (c) 2018 Nicholas E. Buglak et al. This is an open access article distributed under the Creative Commons Attribution License, which permits unrestricted use, distribution, and reproduction in any medium, provided the original work is properly cited.

\begin{abstract}
Reactive oxygen and nitrogen species are indispensable in cellular physiology and signaling. Overproduction of these reactive species or failure to maintain their levels within the physiological range results in cellular redox dysfunction, often termed cellular oxidative stress. Redox dysfunction in turn is at the molecular basis of disease etiology and progression. Accordingly, antioxidant intervention to restore redox homeostasis has been pursued as a therapeutic strategy for cardiovascular disease, cancer, and neurodegenerative disorders among many others. Despite preliminary success in cellular and animal models, redoxbased interventions have virtually been ineffective in clinical trials. We propose the fundamental reason for their failure is a flawed delivery approach. Namely, systemic delivery for a geographically local disease limits the effectiveness of the antioxidant. We take a critical look at the literature and evaluate successful and unsuccessful approaches to translation of redox intervention to the clinical arena, including dose, patient selection, and delivery approach. We argue that when interpreting a failed antioxidant-based clinical trial, it is crucial to take into account these variables and importantly, whether the drug had an effect on the redox status. Finally, we propose that local and targeted delivery hold promise to translate redox-based therapies from the bench to the bedside.
\end{abstract}

\section{Introduction}

Redox reactions are at the center of cellular metabolism and signaling and result in the production of reactive species [1]. Reactive species that stem from oxygen reduction reactions are called reactive oxygen species (ROS) and include free radical and nonradical molecules such as hydroxyl radical $\left(\mathrm{HO}^{\bullet}\right)$, peroxyl $\left(\mathrm{RO}_{2}{ }^{\bullet}\right)$, superoxide $\left(\mathrm{O}_{2}{ }^{--}\right)$, singlet oxygen $\left({ }^{1} \mathrm{O}_{2}\right)$, and hydrogen peroxide $\left(\mathrm{H}_{2} \mathrm{O}_{2}\right)$ [2]. Reactive species that stem from nitric oxide metabolism are called reactive nitrogen species (RNS) and include free radical and nonradical molecules such as nitric oxide ( $N \textrm{NO})$ itself, nitrite $\left(\mathrm{NO}_{2}^{-}\right)$, nitrogen dioxide $\left({ }^{\circ} \mathrm{NO}_{2}\right)$, peroxynitrite $\left(\mathrm{ONOO}^{-}\right)$, dinitrogen trioxide $\left(\mathrm{N}_{2} \mathrm{O}_{3}\right)$, and alky peroxynitrite (ONOOR) [2]. These species are highly reactive and therefore are capable of forming reversible and irreversible interactions with many different macromolecules throughout the body. Under physiological conditions, the reactive species are in balance with antioxidant defenses which enzymatically and nonenzymatically maintain redox homeostasis. In homeostasis, reactive species fulfill their critical role in cell signaling, migration, proliferation, and metabolism. If the redox balance is skewed towards the reactive species however, either from their overproduction or antioxidant depletion, a pathological condition can ensue. Exposure to cigarette smoke [3], various air pollutants [4, 5], 
UV radiation [6], xenobiotics [7], alcohol consumption [8], and different diseases can further exacerbate the pathological cellular state. Consequently, the prolonged redox imbalance can cause aberrant DNA modifications [9], lipid peroxidation [10], peptide chain fragmentation [11], and alterations in signal transduction [12]. This state of cellular redox imbalance, as ROS and RNS overwhelm defense mechanisms, is often referred to as oxidative stress.

Disruption in redox homeostasis can result in undesirable molecular interactions throughout the cell. Impairment at the molecular level can lead to defective organelles, which can translate into cellular dysfunction. In turn, this can cause tissue incompetence ultimately resulting in the development of organ-specific or systemic disease. For this reason, a component of redox dysfunction has been linked to almost all disease states $[13,14]$ including asthma, hypertension, carcinoma, leukemia, diabetes, Alzheimer's disease, autoimmunity, and infection. The implication of a causative role of ROS and RNS in disease development has led to many studies and clinical trials using antioxidant molecules as therapeutics. Despite our understanding of the biochemical interaction of reactive species and their associations with disease onset, causality has yet to be fully elucidated. It is because of this poorly understood and missing connection that most redox-based therapies have largely been unsuccessful. For the purposes of this review, we evaluate the research with the assumption that reactive species have a causal role in disease onset. Accordingly, we chose to review a range of redox-based molecules, from micronutrients, which have been trialed for decades, to new and emerging small molecules currently entering clinical trials for the first time. Additionally, we highlight cell-mediated drug delivery as a novel approach for administering these therapeutics. Ultimately, this review aims to rationalize the reasons as to why few redox-based therapies succeed.

\section{Localized and Targeted versus Systemic Therapy Application}

Failure of therapies to date can be attributed to improper route of drug administration, a discrepancy between preventative and remission therapy, wrong dose to achieve desired effect, or the wrong choice in redox-active molecule due to the vast array of reactive moieties between redox-active compounds. We propose that a fundamental issue with most therapeutic approaches up to now has been their method of delivery. For instance, systemic delivery of an antioxidant for the treatment of a geographically local redox imbalance, as with tumors or atherosclerotic lesions, simply may not deliver the therapeutic concentration to the diseased site. The route of administration may not have been fully evaluated or the metabolism of that antioxidant formulation may not have been properly understood before trials began. Moreover, the redox-active therapeutic may interact with and disrupt systems currently at redox homeostasis. This could lead to a state of local reductive or oxidative stress outside of the diseased area as many "antioxidants" have a prooxidant capacity depending on their concentration and redox environment. Following this notion, systemic delivery of antioxidants to treat a disease with systemic redox imbalance, as in diabetes, may yield the desirable effect. For conditions with localized redox imbalance, however, we suggest the necessity of developing locally delivered or targeted therapeutic strategies that deliver the redox intervention directly and preferentially to the site of disease, hence addressing the redox dysfunction in a local and targeted manner.

\section{Micronutrients}

Micronutrients are readily obtained through the diet and were among the first molecules with antioxidant properties to be identified. Their chemical structures have redoxsensitive functional groups or radical scavenging moieties. Additionally, some have the capacity to recycle endogenous antioxidants. These molecules were also the first to be trialed as therapeutics. Herein, we discuss several recent trials with the ubiquitous alpha-lipoic acid as well as vitamins $\mathrm{A}, \mathrm{B}_{12}, \mathrm{C}$, and $\mathrm{E}$.

3.1. Vitamin C. Vitamin C, also known as ascorbic acid or ascorbate, is a water-soluble compound synthesized from glucose by most animals and galactose by plants. Humans and apes are among the few animals that lack the key enzyme required for vitamin $\mathrm{C}$ biosynthesis, $\mathrm{L}$-gulonolactone oxidase [15]. As such, ascorbate is obtained externally through the diet or by supplementation. Among its many physiological functions, ascorbate acts as a cofactor for neurotransmitter synthesis as well as collagen synthesis and maintenance [16]. As an antioxidant, ascorbate is capable of recycling oxidized vitamin E to its reduced form [17] and scavenging many different ROS and RNS. The preclinical and clinical studies discussed herein are summarized in Table 1.

Work done by Schoenfeld et al. [18] revitalized the therapeutic potential of ascorbate in treating cancer by describing a potential new mechanism in non-small-cell lung cancer (NSCLC) and glioblastoma (GBM). Cellular work using two NSCLC and two GBM cell lines showed that ascorbate selectively sensitizes these cancer cells to chemotherapeutics and radiation therapy compared to primary bronchial epithelial cells and normal human astrocytes [18]. As previously mentioned, antioxidants can have a prooxidant capacity depending on their redox environment. Here, ascorbate treatment increased steady-state levels of hydrogen peroxide $\left(\mathrm{H}_{2} \mathrm{O}_{2}\right)$ and labile iron levels in both cancer cell types, but not in noncancerous cells [18]. The enhanced cancer cell-ascorbate toxicity could be inhibited by preincubation with iron chelators or with catalase, which breaks down $\mathrm{H}_{2} \mathrm{O}_{2}$. Meanwhile, preincubation with EDTA [18], a known enhancer of iron redox cycling, further increased cancer cell-specific toxicity. Lane et al. [19] reported that ascorbate may also increase intracellular iron uptake by acting on transferrin receptors. The cancer-specific toxicity in vitro was recapitulated in mouse xenograft models by Schoenfeld et al. [18] for both NSCLC and GBM using combinations of radiochemotherapy with intraperitoneal injections of ascorbate. Animals treated with all three therapies, compared to radiochemotherapy or ascorbate alone, 
Table 1: Preclinical and clinical studies using vitamin C.

\begin{tabular}{|c|c|c|}
\hline Route & $\begin{array}{l}\text { Vitamin C } \\
\text { Results }\end{array}$ & Reference \\
\hline \multicolumn{3}{|c|}{ Preclinical studies } \\
\hline In vitro & Pancreatic cancer cell $\mathrm{H}_{2} \mathrm{O}_{2}$ production increases susceptibility to therapeutic effect of vitamin $\mathrm{C}$ & {$[20]$} \\
\hline I.P. & $\begin{array}{c}\text { Maintaining a } 20 \mathrm{mM} \text { plasma concentration of vitamin } \mathrm{C} \text { is optimal to obtain a therapeutic effect from } \\
\text { vitamin } \mathrm{C} \text { in an induced-tumor mouse model }\end{array}$ & {$[20]$} \\
\hline In vitro & Vitamin C increases intracellular iron uptake in HUVECs as well as in multiple human cancer cell lines & [19] \\
\hline In vitro & $\begin{array}{l}\text { Vitamin } \mathrm{C} \text { selectively sensitizes non-small-cell lung cancer and glioblastoma cells to radiation and } \\
\text { chemotherapy, while increasing labile iron and } \mathrm{H}_{2} \mathrm{O}_{2} \text { levels }\end{array}$ & {$[18]$} \\
\hline \multicolumn{3}{|c|}{ Clinical studies } \\
\hline $\begin{array}{l}1.25 \mathrm{~g} \text { (oral) } \\
50 \mathrm{~g} \text { (I.V.) }\end{array}$ & Orally administered vitamin $\mathrm{C}$ unable to maintain therapeutic plasma concentration & {$[21]$} \\
\hline $\begin{array}{l}15-125 \mathrm{~g} \\
\text { I.V. }\end{array}$ & $\begin{array}{l}\text { High-dose infusion of vitamin C with gemcitabine in stage IV pancreatic cancer patients could achieve } \\
\text { stable plasma levels of } 20 \mathrm{mM} \text { while increasing the mean survival time }\end{array}$ & {$[23]$} \\
\hline $\begin{array}{l}75 \mathrm{~g} \\
\text { I.V. }\end{array}$ & $\begin{array}{c}\text { Vitamin C infusions were well tolerated and increased average progression-free survival in glioblastoma } \\
\text { patients and control rate of disease in non-small-cell lung cancer patients }\end{array}$ & {$[18]$} \\
\hline
\end{tabular}

I.P.: intraperitoneal; I.V.: intravenous.

exhibited an increased rate of survival [18]. The authors proposed a mechanism inherent to cancer cells whereby superoxide $\left(\mathrm{O}_{2}{ }^{\bullet-}\right)$ and $\mathrm{H}_{2} \mathrm{O}_{2}$ disrupt cellular iron metabolism with ascorbate oxidation further increasing intracellular $\mathrm{H}_{2} \mathrm{O}_{2}$ and labile iron levels. Through the Fenton reaction, $\mathrm{H}_{2} \mathrm{O}_{2}$ and iron react causing an increased oxidative burden and resulting in the observed cancer-specific ascorbate toxicity [18]. A phase I clinical trial for GBM patients treated with radiation, temozolomide, and intravenous ascorbate infusions showed that ascorbate was well tolerated and increased the average progression-free survival compared to the historical median [18]. Additionally, a phase II clinical trial for NSCLC patients treated with chemotherapy and ascorbate infusions reported an increased disease control rate compared with historical controls [18]. Unfortunately, the efficacy of ascorbate infusions in concert with radiochemotherapy has yet to be determined due to the limited sample size in these two studies.

The ability of ascorbate to specifically target NSCLC and GBM cancer cells without affecting the redox homeostasis of healthy cells makes systemic intravenous administration possible. In this example, the redox modulation happens only in tumor cells where iron metabolism is disrupted, and in this sense, this is an example of targeted therapy. However, a consistent plasma concentration must be maintained and $20 \mathrm{mM}$ has been proposed as the therapeutic optimum [20]. Meanwhile, oral administration is incapable of obtaining and maintaining the required plasma concentrations $[21,22]$. These data show the importance of administration route to achieve the desired effect. In the PACMAN study, a phase I clinical trial for stage IV pancreatic cancer, Welsh et al. [23] showed that infusion of high doses of ascorbate together with gemcitabine achieved stable plasma levels around $20 \mathrm{mM}$. The PACMAN study also revealed that systemically administered ascorbate did not cause an alteration in the erythrocyte reduced to oxidized glutathione (GSH:GSSG) ratio nor in plasma levels of $\mathrm{F}_{2}$-isoprostane [23], an arachidonic acid peroxidation product commonly used as a biomarker. The mean survival was 12 months, almost double the historic median for gemcitabine-treated patients [23], yet due to the small sample size, no statistically significant conclusion about efficacy can be made. As of June 2017, the PACMAN study is scheduled to enter phase II (NCT02905578), with phase II trials for NSCLC (NCT02905591) and GBM (NCT02344355) scheduled as well. Hopefully, these upcoming and future trials will identify if an intravenous vitamin $\mathrm{C}$ formulation is an effective targeted systemic delivery for treating a geographically local redox imbalance.

3.2. Vitamin E. E vitamins are a group of fat-soluble compounds classified as saturated tocopherols or unsaturated tocotrienols, with $\alpha, \beta, \gamma$, and $\delta$ isoforms within each group. The most biologically active vitamin E compound in humans is $\alpha$-tocopherol. Therefore, $\alpha$-tocopherol will be the vitamin $\mathrm{E}$ isoform described henceforth unless otherwise specified. Interestingly, vitamin $\mathrm{E}$ has been hypothesized to act only as a peroxyl $\left(\mathrm{RO}_{2}{ }^{\circ}\right)$ radical scavenger $[17,24]$. As such, vitamin $\mathrm{E}$ effectively prevents the peroxyl radical chain reaction-driven lipid peroxidation. A summary of the preclinical and clinical studies discussed can be seen in Table 2 .

Being fat soluble, vitamin $\mathrm{E}$ is mainly transported by lipoproteins where it prevents lipoprotein oxidation [25] - a redox reaction that drives atherosclerotic plaque development. An atherosclerosis model of rabbits fed a highcholesterol diet showed that dietary vitamin E supplementation significantly reduced plaque development [26]. Tang et al. showed that vitamin E supplementation reduced plaque development in apolipoprotein $\mathrm{E}$ knockout $\left(\mathrm{ApoE}^{-/-}\right)$ mice when administered early, between 6 and 22 weeks of age, yet had no effect on reducing advanced lesions when administered at 30 or 38 weeks [27]. It is worth noting here that $\alpha$-tocopherol has been shown to have limited antiatherosclerotic potential in rodent models [28]. In both the rabbit model and the $\mathrm{ApoE}^{-1-}$ mice, vitamin E activated the nuclear factor erythroid 2-related factor 2 (Nrf2) pathway 
TABle 2: Preclinical and clinical studies using vitamin E.

\begin{tabular}{|c|c|c|}
\hline Route & $\begin{array}{r}\text { Vitamin E } \\
\text { Results }\end{array}$ & Reference \\
\hline \multicolumn{3}{|c|}{ Preclinical studies } \\
\hline In vitro & $\begin{array}{c}\alpha \text {-Tocopherol activates Nrf2 in human retinal pigment epithelial cell line ARPE-19, thus inducing } \\
\text { transcription of phase II enzymes }\end{array}$ & {$[32]$} \\
\hline Oral & $\begin{array}{c}16 \text { weeks of } 1500 \mathrm{IU} \text { vitamin } \mathrm{E} \text { daily is able to rescue } \mathrm{Nrf2} \text { function in alveolar macrophages from human } \\
\text { atopic asthmatics }\end{array}$ & [33] \\
\hline In vitro & $\begin{array}{l}\alpha \text {-Tocopheryl succinate activates Nrf2 in PC3 prostate cancer cell line which inhibits NF- } \kappa \mathrm{B} \text { nuclear } \\
\text { translocation and neoplastic activity }\end{array}$ & {$[31]$} \\
\hline $\begin{array}{l}\text { Oral } \\
\text { I.M. }\end{array}$ & Vitamin E significantly reduced atherosclerotic plaque progression in rabbits fed a high-cholesterol diet & {$[26]$} \\
\hline Oral & Vitamin E significantly reduced atherosclerotic plaque progression in $\mathrm{ApoE}^{-/-}$mice & {$[27]$} \\
\hline Oral & $\begin{array}{c}\text { Vitamin E deficiency disrupts grass carp growth and physiology while vitamin E supplementation is able to } \\
\text { reverse the negative effects }\end{array}$ & {$[34]$} \\
\hline \multicolumn{3}{|c|}{ Clinical studies } \\
\hline $\begin{array}{l}400-800 \mathrm{IU} \\
\text { Oral }\end{array}$ & $\begin{array}{c}\text { Daily vitamin E supplementation showed substantial reduction in nonfatal myocardial infarction in patients } \\
\text { with angiographically proven coronary atherosclerosis, yet no significant benefit on risk of cardiovascular } \\
\text { death was observed }\end{array}$ & {$[38]$} \\
\hline $\begin{array}{l}400 \mathrm{IU} \\
\text { Oral }\end{array}$ & $\begin{array}{l}\text { 4-6 years of daily vitamin E supplementation showed no therapeutic benefit on cardiovascular events in } \\
\text { high-risk patients } 55 \text { years of age or older }\end{array}$ & {$[39]$} \\
\hline $\begin{array}{l}100-3200 \mathrm{IU} \\
\text { Oral }\end{array}$ & 16 weeks of at least $800 \mathrm{IU} /$ day of vitamin E required to reduce the plasma F2-isoprostane concentration & {$[40]$} \\
\hline $\begin{array}{l}400 \mathrm{IU} \\
\text { Oral }\end{array}$ & $\begin{array}{c}\text { Daily supplementation of vitamin E only therapeutic in type } 2 \text { diabetes with genotype for systemically } \\
\text { elevated oxidative stress }\end{array}$ & {$[41]$} \\
\hline $\begin{array}{l}400 \mathrm{IU} \\
\text { Oral }\end{array}$ & $\begin{array}{l}\text { Hemodialysis patients experienced reduced rate of plasma MDA level increase following } 2 \text { months of } \\
\text { vitamin E supplementation. }\end{array}$ & {$[44]$} \\
\hline $\begin{array}{l}400 \mathrm{mg} \\
\text { Oral }\end{array}$ & $\begin{array}{l}\text { Patients with Down syndrome had their abnormal superoxide dismutase and catalase activity as well as low } \\
\text { levels of reduced glutathione returned to physiological levels following vitamin E supplementation }\end{array}$ & {$[45]$} \\
\hline $\begin{array}{l}2000 \mathrm{IU} \\
\text { Oral }\end{array}$ & Daily high dose of vitamin E slowed the functional decline of Alzheimer's disease patients & {$[46]$} \\
\hline $\begin{array}{l}400 \mathrm{IU} \\
\text { Oral }\end{array}$ & $\begin{array}{l}\text { Eight weeks of daily vitamin E supplementation increased paraoxonase-1 enzyme activity but did not lower } \\
\text { serum malondialdehyde levels in type } 2 \text { diabetic patients }\end{array}$ & {$[43]$} \\
\hline $\begin{array}{l}300 \mathrm{mg} \\
\text { Oral }\end{array}$ & $\begin{array}{l}\text { Three months of daily vitamin E supplementation significantly reduced serum malondialdehyde levels in } \\
\text { insulin-dependent type } 2 \text { diabetic patients }\end{array}$ & {$[42]$} \\
\hline $\begin{array}{l}\text { Ointment } \\
\text { S.C. }\end{array}$ & $\begin{array}{c}\text { Patients undergoing colorectal cancer surgery exposed to vitamin } \mathrm{E} \text { at the surgical site experienced a reduced } \\
\text { rate of surgical site infection and lowered inflammatory response }\end{array}$ & {$[47]$} \\
\hline
\end{tabular}

I.M.: intramuscular; S.C.: subcutaneous.

$[26,27]$, which regulates the expression of antioxidant enzymes [29]. Specifically, Bozaykut et al. [26] showed an increase in the expression of glutathione S-transferase, one downstream enzyme of $\mathrm{Nrf} 2$, which is responsible for initiating the function of glutathione (GSH) [30], another major intracellular antioxidant. The Nrf2 pathway has now also been implicated as a vitamin E therapeutic mechanism in in vitro models of cancer [31] and macular degeneration [32] as well as in in vivo allergy [33] and developmental [34] studies. Furthermore, vitamin E has also been shown to increase peroxisome proliferatoractivated receptor gamma $(\operatorname{PPAR} \gamma)$ expression [26, 27]. PPAR $\gamma$ is one isoform of the PPAR ligand-activated transcription factors whose activation can be protective against cardiovascular diseases, neurodegenerative disorders, and cancer [35-37]. Thus, Nrf2 and PPAR activation reveal indirect antioxidant properties of vitamin $\mathrm{E}$, which when paired with the direct radical scavenging ability make for a promising therapeutic.

CHAOS [38] and HOPE [39] were two of the first trials using vitamin $\mathrm{E}$ in prevention of cardiovascular disease. Both of these trials showed no cardiovascular benefit, which can potentially be attributed to the $400 \mathrm{IU} /$ day [39] or up to $800 \mathrm{IU} /$ day [38] doses used. In 2007, Roberts et al. [40] conducted both a dose-ranging and time-course study in hypercholesterolemic patients to evaluate the pharmacology of vitamin E. This was a beneficial study for future clinical trials as they revealed two critical dosing aspects. First, it took 16 weeks of daily dosing to reduce the plasma $\mathrm{F}_{2}$-isoprostane concentration [40]. Second, this reduction was only significantly obtained at $1600 \mathrm{IU} /$ day and $3200 \mathrm{IU} /$ day, with a trend towards reduction at $800 \mathrm{IU} /$ day [40]. At the largest dose of natural vitamin E (3200 IU/day), there was a $49 \%$ reduction in plasma $\mathrm{F}_{2}$-isoprostanes, which led the authors to suggest 
TAble 3: Preclinical and clinical studies using alpha-lipoic acid.

\begin{tabular}{|c|c|c|}
\hline Route & $\begin{array}{l}\text { Alpha-lipoic acid } \\
\text { Results }\end{array}$ & Reference \\
\hline \multicolumn{3}{|c|}{ Preclinical studies } \\
\hline Oral & ALA slowed the rate of plaque progression in a diet-induced rabbit atherosclerosis model & {$[56]$} \\
\hline I.P. & $\begin{array}{c}\text { ALA reduced lesion size in a diet-induced atherosclerotic mouse model. ALA also reduced vascular smooth } \\
\text { muscle cell proliferation and migration in vitro }\end{array}$ & [59] \\
\hline I.V. & $\begin{array}{l}\text { Spleen weight/body weight ratio, levels of } \mathrm{H}_{2} \mathrm{O}_{2} \text {, lipid peroxidation, and levels of reduced glutathione } \\
\text { returned to physiological levels in LPS-treated rats following ALA injection }\end{array}$ & [52] \\
\hline Oral & $\begin{array}{c}\text { ALA restored GSH, SOD, and catalase plasma concentrations to physiological levels in a pesticide-induced } \\
\text { oxidative stress rat model }\end{array}$ & [54] \\
\hline S.C. & $\begin{array}{l}\text { ALA restored SOD and catalase concentrations to physiological levels in brain tissue of a phenylketonuria } \\
\text { rat model }\end{array}$ & [55] \\
\hline I.P. & Kidney mitochondrial function restored in LPS-treated rats following ALA exposure & [53] \\
\hline \multicolumn{3}{|l|}{ Clinical studies } \\
\hline $\begin{array}{l}600-1800 \mathrm{mg} \\
\text { Oral }\end{array}$ & $\begin{array}{l}\text { Five weeks of daily ALA supplementation alleviated the pain experienced by diabetics suffering from distal } \\
\text { symmetric polyneuropathy. }\end{array}$ & [61] \\
\hline $\begin{array}{l}600 \mathrm{mg} \\
\text { Oral }\end{array}$ & $\begin{array}{l}\text { Four years of daily ALA supplementation improved neuropathic conditions of diabetics suffering from } \\
\text { polyneuropathy and the } 600 \mathrm{mg} \text { dose was well tolerated for an extended period of time }\end{array}$ & [63] \\
\hline $\begin{array}{l}600 \mathrm{mg} \\
\text { Oral }\end{array}$ & $\begin{array}{c}20 \text { weeks of daily ALA supplementation alleviated the pain experienced by diabetics suffering } \\
\text { from polyneuropathy }\end{array}$ & [62] \\
\hline
\end{tabular}

I.P.: intraperitoneal; I.V.: intravenous; S.C.: subcutaneous.

that the antioxidant potency of vitamin E may not be biologically effective [40]. These studies taken together underline the relevance of selecting the appropriate dose and regimen to achieve a significant effect on redox homeostasis. Only after determining that a treatment actually improves redox function can we assess its antioxidant effect on disease progression and clinical outcomes. A study by Milman et al. [41] showed that daily vitamin E supplementation only had cardiovascular benefit in type 2 diabetics having a haptoglobin 2-2 genotype. The protein produced by this genotype is associated with elevated systemic oxidative stress due to its inferior function compared to the haptoglobin 1-1 genotype protein product. Several studies measured serum malondialdehyde (MDA) levels, a lipid peroxidation product, to assess the benefit of oral vitamin $\mathrm{E}$ supplementation. Although a reduction in plasma MDA levels was frequently observed, this systemic decrease in a lipid peroxidation marker did not correlate with improvement of clinical symptoms [42-44]. Thus, translating cellular and animal model work into an effective human therapeutic while also identifying the proper patient population that benefits from the given therapy and relevant biomarkers makes clinical trial design rather difficult.

Patients with ranging neurological disorders have been reported to experience increased levels of systemic oxidative stress [13]. Parisotto et al. [45] compared the blood antioxidant status of children with Down syndrome (DS) before and after 6 months of daily vitamin $C$ and E supplementation. The study showed that DS patients had elevated superoxide dismutase (SOD) and catalase activity yet lower GSH levels, and all could be returned to physiological levels after supplementation [45]. A randomized, doubleblind, placebo-controlled, parallel-group trial reported that a high dose of 2000 IU/day of vitamin E slowed the functional decline of patients with mild to moderate Alzheimer's disease [46]. Both studies highlight how a systemically administered antioxidant can reduce systemic redox imbalance and alleviate symptoms experienced by individuals with neurological disease.

Lastly, Alias et al. [47] showed that subcutaneous application of vitamin $\mathrm{E}$ acetate ointment reduced the rate of surgical site infection in colorectal cancer surgery patients, while simultaneously lowering the inflammatory response. The patients underwent a laparoscopic, or minimally invasive, surgery. Patients who received vitamin E treatment had decreased C-reactive protein and a reduced white blood cell count 48 hours after surgery and reported lower postoperative pain [47]. This is an excellent example of a preventative strategy for localized delivery of an antioxidant to mitigate the onset of local redox imbalance.

3.3. Alpha-Lipoic Acid. The disulfide fatty acid $\alpha$-lipoic acid (ALA) is an amphipathic molecule both naturally synthesized and obtained through the diet. Virtually ubiquitous throughout the body, ALA and its reduced form, dihydrolipoic acid, have been reported to have numerous antioxidant and anti-inflammatory properties [48]. The therapeutic potential thus stems from the capability of ALA to scavenge reactive species $[49,50]$, recycle glutathione $(\mathrm{GSH})$ and vitamins $\mathrm{C}$ and $\mathrm{E}$ [49], chelate divalent transient metal ions [50], and increase glucose uptake [51]. The preclinical and clinical studies described from here on are summarized in Table 3.

Goraca et al. [52] evaluated ALA treatment in a rat model of bacterial infection using lipopolysaccharide (LPS), a major component of the outer membrane of gram-negative bacteria. The spleen of LPS-treated rats had increased levels of hydrogen peroxide $\left(\mathrm{H}_{2} \mathrm{O}_{2}\right)$ and lipid peroxidation, an 
increased spleen weight/body weight ratio, and decreased levels of GSH [52]. All three of these markers were returned to physiological levels after intravenous ALA injection [52] suggesting that ALA can protect the spleen from an exaggerated inflammatory response. Cimolai et al. [53] showed that intraperitoneal-injected ALA could restore kidney mitochondrial function in rats exposed to LPS. Mignini et al. [54] used a pesticide-induced oxidative stress rat model to evaluate the effects of oral ALA supplementation and showed that ALA could increase plasma GSH concentrations. Additionally, ALA restored SOD and catalase plasma concentrations to physiological levels [54]. Subcutaneous delivery of ALA restored SOD and catalase to physiological levels in the brain tissue of a phenylketonuria rat model [55], a neurological disease that causes systemic phenylalanine accumulation and oxidative stress. Orally administered ALA slowed the rate of plaque progression, lowered plasma $\mathrm{F}_{2}$-isoprostane levels, decreased lipid accumulation, and reduced collagen deposition in a diet-induced rabbit atherosclerosis model [56]. Furthermore, ALA decreased mRNA expression of vascular cell adhesion molecule-1 (VCAM-1) and of intracellular adhesion molecule-1 (ICAM-1) and reduced NF- $\kappa$ B pathway activity in the rabbit model [56]; all of which are proinflammatory factors associated with plaque development $[57,58]$. A dietinduced atherosclerotic mouse model also showed that intraperitoneal ALA delivery could reduce lesion size and VCAM-1 and ICAM-1 expression [59]. Lee et al. [59] showed that ALA could reduce vascular smooth muscle proliferation and migration in vitro by attenuating the Ras-MEK1/2-ERK1/2 proliferative pathway. As of June 2017, phase III clinical trials using ALA for atherosclerosis treatment (NCT00764270) and heart disease prevention (NCT00765310) are ongoing.

ALA supplementation has been particularly successful in diabetic patients and has been prescribed for the treatment of diabetic polyneuropathy in Germany for decades [50]. In 2004, Ziegler et al. [60] assessed the role of oxidative stress in the development of diabetic polyneuropathy, a complex neuronal disorder associated with increased morbidity and mortality. Their results showed that systemic redox imbalance was more prominent in diabetics with polyneuropathy than in diabetics without polyneuropathy [60]. The SYDNEY 2 clinical trial assessed the efficacy of orally administered ALA in alleviating pain experienced by diabetic patients with distal symmetric polyneuropathy [61]. The primary measurement in the SYDNEY 2 trial was total symptom score (TSS), a summation of factors related to neuropathic pain where higher scores indicate an increased level of experienced pain. The results revealed that $600 \mathrm{mg}$ of ALA administered orally for 5 weeks improved the positive sensory symptoms of diabetic patients [61]. Similar findings were described by Garcia-Alcala et al., [62] who reported that 20 weeks of ALA treatment resulted in a continuous reduction in TSS. NATHAN 1 was a four-year clinical trial that further assessed ALA treatment for polyneuropathy as well as the safety of prolonged oral administration of $600 \mathrm{mg}$ of ALA [63]. This trial used several comprehensive analyses alongside TSS such as the neuropathy impairment score (NIS)
[64] and the NIS lower limbs score to measure therapeutic outcomes without any direct measurements of changes in redox markers. Improvement of neuropathic impairments, particularly small fiber and muscular function, was ultimately reported, and the $600 \mathrm{mg}$ dose was well tolerated by patients [63]. We guide the readers to an extensive review by Papanas and Ziegler [65] of more trials and relevant meta-analyses regarding ALA in diabetic neuropathy. The success seen in these trials can likely be attributed to the hydrophilic and lipophilic nature of ALA as well as to the delivery route in treating a disorder that stems from a systemic redox imbalance.

3.4. Vitamin A. A vitamins are a group of unsaturated, fatsoluble organic molecules that elicit pleiotropic effects throughout the body. Physiologically, vitamin A regulates energy homeostasis, lipid metabolism, the immune response, and gene expression for cellular development and differentiation [66-68]. The major signaling mechanism for the regulatory actions of vitamin $\mathrm{A}$ is through nuclear retinoic acid receptors. However, signaling through Janus kinase (JAK)/signal transducer and activator of transcription (STAT), mitogen-activated protein kinase (MAPK), and PPAR pathways have also been described [67]. Vitamin A quenches singlet oxygen $\left({ }^{1} \mathrm{O}_{2}\right)$ [69] and prevents lipid peroxidation by scavenging peroxyl $\left(\mathrm{RO}_{2}{ }^{\circ}\right)$ radicals [70], similar to vitamin E. Furthermore, the major active metabolite of vitamin A-retinoic acid-acts as a precursor for rhodopsin, the light-sensitive pigment in the eye responsible for phototransduction [71]. Retinoic acid is obtained through the diet from animal-derived food or from plantderived precursors like $\beta$-carotene and lycopene. Clinical studies using vitamin A are summarized in Table 4.

In accordance with the pleiotropic properties on cellular homeostasis, vitamin A was trialed and is now accepted as a therapeutic for various skin-related conditions. Topically applied $\beta$-carotene protected human skin from IR-generated reactive species [72] and orally administered $\beta$-carotene reduced UV-induced skin lesions [73]. A randomized, double-blind, vehicle-controlled, clinical trial showed that topical retinol, the alcohol retinoic acid derivative, applied three times a week for 24 weeks reduced the appearance of aging-related fine wrinkles in elderly volunteers by increasing the dermal matrix [74]. Furthermore, topical application of tretinoin or all-trans retinoic acid has long been prescribed for the treatment of acne and photoaging $[75,76]$ and is more effective than orally administered tretinoin in cases of photoaging [77]. The role of these and more vitamin A derivatives in treating skin disease has been reviewed elsewhere [78]. The success of topical vitamin A application provides evidence that identifying the proper antioxidant for a given condition combined with an administration route that localizes the redox intervention results in a successful antioxidant therapy.

3.5. Vitamin $B_{12}$. Vitamin $B_{12}$ derivatives or cobalamins (Cbl) are soluble macrocycles belonging to the corrinoid family with a cobalt atom tethered in the center of the corrin plane. They are essential cofactors for two enzymes in 
TABLe 4: Clinical studies using vitamin A.

\begin{tabular}{|c|c|c|}
\hline Route & $\begin{array}{r}\text { Vitamin A } \\
\text { Results }\end{array}$ & Reference \\
\hline \multicolumn{3}{|c|}{ Clinical studies } \\
\hline $\begin{array}{l}24 \mathrm{mg} \\
\text { Oral }\end{array}$ & 12 weeks of daily oral vitamin A reduced UV-induced skin lesions & [73] \\
\hline $\begin{array}{l}0.4 \% \text { lotion } \\
\text { Topical }\end{array}$ & Topical vitamin A application three times a week for 24 weeks reduced aging-related wrinkles & {$[74]$} \\
\hline $\begin{array}{l}0.2 \% \text { lotion } \\
\text { Topical }\end{array}$ & Topical vitamin A protects skin from IR-generated reactive species & {$[72]$} \\
\hline $\begin{array}{l}20 \mathrm{mg} \\
\text { Oral } \\
0.05 \% \text { lotion } \\
\text { Topical }\end{array}$ & Topical vitamin A more effective in treating photoaging than orally administered & [77] \\
\hline
\end{tabular}

TABle 5: Preclinical and clinical studies using vitamin $B_{12}$

\begin{tabular}{|c|c|c|}
\hline Route & $\begin{array}{c}\text { Vitamin } \mathrm{B}_{12} \text { (cobalamin) } \\
\text { Results }\end{array}$ & Reference \\
\hline \multicolumn{3}{|c|}{ Preclinical studies } \\
\hline In vitro & $\begin{array}{l}\text { Pulse radiolysis determined that the rate constant between } \mathrm{Cob}(\mathrm{II}) \text { alamin and superoxide }\left(\mathrm{O}_{2}^{--}\right) \text {is } 6.8 \times 10^{8} \mathrm{M}^{-1} \mathrm{~s}^{-1} \text {, } \\
\text { which is within an order of magnitude of cytosolic and mitochondrial superoxide dismutase (SOD) }\end{array}$ & [79] \\
\hline In vitro & $\mathrm{Cob}(\mathrm{II})$ alamin reacts with $\mathrm{O}_{2}{ }^{\bullet-}$ at a rate similar to that of the SOD & {$[80]$} \\
\hline In vitro & $\begin{array}{c}\text { Cyanocobalamin treatment inhibited } \mathrm{O}_{2}{ }^{--} \text {-induced damage in human aortic endothelial cells by scavenging } \\
\text { intracellular } \mathrm{O}_{2}^{\bullet-}\end{array}$ & {$[83]$} \\
\hline
\end{tabular}

Clinical studies

$0.5 \mathrm{mg}$ Daily supplementation with folic acid, vitamin $\mathrm{B}_{6}$, and vitamin $\mathrm{B}_{12}$ for one year significantly reduced the carotid

Oral intima-media thickness, a marker of atherosclerosis, in at-risk patients

$0.4 \mathrm{mg}$ Six months of daily folic acid and vitamin $\mathrm{B}_{12}$ supplementation improved coronary endothelial function in patients

Oral at risk for coronary artery disease

$0.4 \mathrm{mg}$ Two years of daily supplementation with folic acid and vitamin $\mathrm{B}_{12}$ significantly increased coronary blood flow in

Oral patients with stable coronary artery disease

25 or

$0.5 \mathrm{mg}$

Daily ultrahigh-dose injections $(25 \mathrm{mg}$ ) of methylcobalamin improved the compound muscle action potentials of patients with amyotrophic lateral sclerosis

I.M.

Eyedrops Eyedrops containing $0.15 \%$ hyaluronic acid and vitamin $\mathrm{B}_{12}$ reduced oxidative stress markers in the conjunctiva (mucous membrane covering eye) and improved the overall symptoms of patients with chronic dry eye

I.M.: intramuscular.

mammals: mitochondrial methylmalonyl-CoA mutase and cytosolic methionine synthase. The central cobalt can change its oxidation state between +3 (cob(III)alamin), +2 ( $\operatorname{cob}(\mathrm{II}) \mathrm{a}$ lamin), and +1 (cob(I)alamin), which makes these compounds redox active. Moreover, it has been shown that $\mathrm{Cbl}$ reacts with $\mathrm{O}_{2}{ }^{--}$at rates comparable with that of superoxide dismutase $[79,80]$. Hence, it has been suggested that cobalamins modulate inflammation and redox status [81-83] in addition to and independently of their cofactor function. Low serum levels of $\mathrm{B}_{12}$ are prevalent in patients with type 2 diabetes mellitus, and there is an association between low levels of $\mathrm{B}_{12}$ and markers of oxidative dysfunction [84]. Moreover, levels of $\mathrm{B}_{12}$ negatively correlate with fasting glucose, oxidized LDL, and catalase levels in diabetic vegetarians [85]. These findings suggest that Cbl supplementation could be useful in patients with type 2 diabetes mellitus, especially if they are vegetarians, who are at risk of low $\mathrm{B}_{12}$. Preclinical and clinical work with vitamin $B_{12}$ is summarized in Table 5 .

Cobalamin is essential to metabolize homocysteine, an independent risk factor for cardiovascular disease. Hence, researchers have investigated the role of $\mathrm{Cbl}$ in cardiovascular disease. One of us was among the first to characterize a redox effect in vascular cells [83] and suggest that it acted by direct scavenging of $\mathrm{O}_{2}{ }^{\bullet-}$ with a high rate constant [80]. In a randomized placebo-controlled trial, a mix of folate, vitamin $B_{6}$, and vitamin $B_{12}$ reduced the carotid intimamedia thickness in patients at risk of cerebral ischemia [86]. This effect was found to be independent of homocysteine. In a small prospective randomized placebo-controlled trial, Willems et al. [87] demonstrated that treatment with cobalamin in patients with coronary artery disease improved volumetric coronary blood flow. These results 
were later confirmed by Bleie et al. [88] showing an increased coronary blood flow in a patient with stable coronary artery disease treated with cobalamin, suggesting that $\mathrm{B}_{12}$ improves vascular function.

Cobalamin levels are associated with systemic and central nervous system (CNS) markers of redox dysfunction and inflammation, independently of homocysteine levels [82]. In a controlled, double-blinded study in patients with idiopathic osteoarthritis, Flynn et al. [81] found that $\mathrm{Cbl}$ improved handgrip and tenderness compared to NSAID treatment. Regarding effect on the CNS, intramuscular injection of high doses of $\mathrm{Cbl}$ improved muscle action potential amplitude in a small double-blind trial in patients with amyotrophic lateral sclerosis [89].

A successful example of local administration of $\mathrm{Cbl}$ to reduce redox dysfunction and inflammation was published by Macri et al. [90]. They found that eye drops containing hyaluronic acid and vitamin $\mathrm{B}_{12}$ significantly decrease markers of lipid peroxidation and inflammation, improving dry eye symptoms. Although vitamin $B_{12}$ is not classically considered an antioxidant, more evidence accumulates supporting a redox effect of Cbl. Since it is well tolerated and no adverse effects have been reported, exploring further the noncoenzyme and redox effects of $\mathrm{Cbl}$ is a promising therapeutic avenue for cardiovascular, neurological, and inflammatory diseases.

\section{Enzyme Regulators and Mimetics}

The use of stoichiometric antioxidant molecules presents with the problem that they are finite. At the necessary site they may be present in limited concentrations or may not have been recycled after their redox reaction. Accordingly, most cellular redox homeostasis is maintained by enzymes [91]. As we have shown with micronutrients, certain antioxidants can increase enzyme production and function aside from directly inactivating the reactive species. Herein, we analyze several specific enzyme-directed therapeutics and present an overview in Figure 1. Next, we discuss the use of redox enzymes, enzyme mimics, and enzyme regulators.

4.1. NADPH Oxidase Inhibitors. Nicotinamide adenine dinucleotide phosphate (NADPH) oxidases (NOX) are a group of transmembrane enzymes that generate superoxide $\left(\mathrm{O}_{2}{ }^{--}\right)$by transferring electrons from NADPH across a membrane to reduce molecular oxygen [92]. Accordingly, NOX enzymes are present in the plasma membrane, endoplasmic reticulum, mitochondrial membrane, and nuclear membrane, as well as at focal adhesions [93] and invadopodia [94]. In total, there are seven NOX isoforms termed NOX1-5 or DUOX1-2. NOX enzymes are physiologically crucial for the immune response and during angiogenesis; these functions along with enzymatic regulation and localization have been reviewed in extensive detail elsewhere [95]. Pathologically, dysregulated NOX enzymes have been implicated in various cancers [96, 97], neurodegenerative diseases [98], cardiovascular diseases [99], and renal disease [100].
Due to the association of dysregulated NOX with disease onset, it was fitting to pursue direct NOX inhibition as a therapeutic. Triazolopyrimidine derivatives (VAS) and pyrazolopyridine dione derivatives (GKT) are two efficacious small molecule inhibitors that have been reported. VAS and GKT successfully mitigate ROS formation and damage in in vitro and in vivo models of disease [101-105]. These two families, and others not covered in this section, have been extensively reviewed elsewhere [106].

Specifically, GKT137831 is a NOX 1 and 4 inhibitor that has been reported to mitigate renal disease [105], attenuate diabetic nephropathy [102], and suppress cardiac fibroblast activity associated with hypertensive heart disease [104]. A randomized, double-blind, placebo-controlled phase II trial using GKT137831 for treating type 2 diabetes with nephropathy was concluded in 2015 (NCT02010242). The drug developer, Genkyotex, reported that GKT137831 was safe and significantly reduced liver enzyme and inflammatory marker levels, with the results unpublished as of June 2017. Currently, Genkyotex is finalizing a phase II study design to treat the liver disease primary biliary cholangitis with GKT137831.

Meanwhile, VAS2870 a NOX 1, NOX 2, and NOX 4 inhibitor has been reported to have protective properties against brain ischemia in mice [101] and to reduce ROS production and radiation-induced phenotypic changes in human pulmonary artery endothelial cells [103]. One challenge for translating the success of VAS molecules to the clinic is their low solubility. Hecht et al. [107] have potentially solved this issue by developing a method that utilizes spray drying, microemulsification, and cyclodextrin incorporation to enhance the solubility and stability of VAS3947 as a model VAS molecule, for oral administration. Ongoing studies with these two classes of molecules will offer a greater understanding of their pharmacological efficacy and the value of targeted NOX inhibition in disease treatment or prevention.

4.2. Nitric Oxide Synthase Inhibitors. Nitric oxide synthase (NOS) represents a group of enzymes that utilize molecular oxygen and NADPH to oxidize L-arginine producing L-citrulline and nitric oxide ( $\left.{ }^{\circ} \mathrm{NO}\right)$. There are three NOS isoforms termed neuronal NOS (nNOS or NOS I), inducible NOS (iNOS or NOS II), and endothelial NOS (eNOS or NOS III). Exceptions to the general locations and regulatory mechanisms for each isoform have been extensively reviewed elsewhere [108], but generally, nNOS is found throughout the central (CNS) and peripheral (PNS) nervous systems where ${ }^{\circ} \mathrm{NO}$ is implicated in aspects of synaptic plasticity and cellular communication; iNOS is typically found in cells of the immune system where ${ }^{\bullet} \mathrm{NO}$ is responsible for the cell's cytotoxic properties; eNOS is mostly expressed in endothelial cells where ${ }^{\circ} \mathrm{NO}$ causes vasodilation and vasoprotection and prevents platelet aggregation. Therapeutic approaches have been aimed at inhibiting iNOS.

Initially, NOS inhibitors aimed to displace the enzymatic substrate arginine but were clinically ineffective and even increased mortality in the case of L-NMMA treatment for septic shock [109]. To date, the most successful NOS 


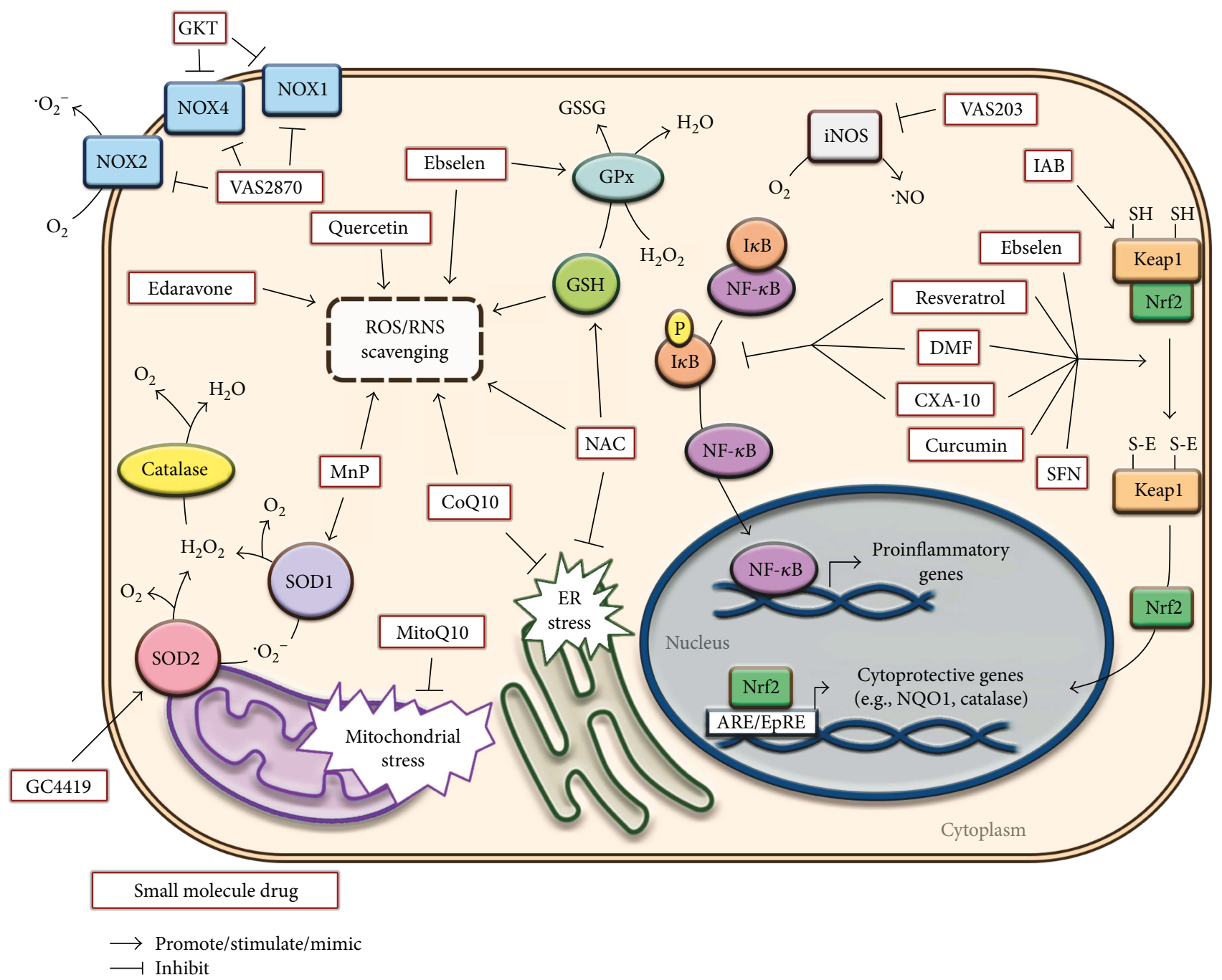

FIGURE 1: A scheme depicting cellular sites of action of several redox interventions. ARE/EpRE: antioxidant response element/electrophile responsive element; CoQ10: coenzyme Q10; CXA-10: 10-nitro-oleic-acid formulation; DMF: dimethyl fumarate; ER: endoplasmic reticulum; GKT: GKT137831; GPx: glutathione peroxidase; GSH: glutathione; IAB: N-iodoacetyl-N-biotinylhexylenediamine; MnP: manganese porphyrins; NAC: N-acetylcysteine; NOS: nitric oxide synthase; NOX: NADPH oxidase; NQO1: NAD(P)H quinone dehydrogenase 1; Nrf2: nuclear factor erythroid 2-related factor 2; RNS: reactive nitrogen species; ROS: reactive oxygen species; SFN: sulforaphane; SOD: superoxide dismutase.

inhibitor is 4-amino-tetrahydrobiopterin (VAS203), developed by Vasopharm, which is an analogue of the redoxsensitive NOS cofactor tetrahydrobiopterin rather than an arginine analogue [110]. VAS203 is an allosteric iNOS inhibitor and is being trialed for the treatment of traumatic brain injury (TBI). TBI has been shown to cause increased iNOS activity in the brain due to a compromised blood-brain barrier, aside from other major complications [111]. An exploratory phase II placebo-controlled, randomized trial named NOSTRA-II determined that VAS203 may have neuroprotective properties and can be safely administered, although there was reversible kidney damage reported in several patients at the highest tested dose $(30 \mathrm{mg} / \mathrm{kg})$ [110]. In light of these findings, a phase I trial to assess renal function impairment in healthy volunteers was concluded in early 2017 with results unreported so far (NCT02992236). As of June 2017, NOSTRA-III-the placebo-controlled, randomized, double-blind phase III trial-is underway to evaluate the efficacy of VAS203 infusions on clinical outcomes of patients with moderate to severe TBI (NCT02794168).

4.3. Superoxide Dismutase Mimetics. Superoxide dismutase (SOD) is a group of metal-containing enzymes that convert superoxide $\left(\mathrm{O}_{2}{ }^{--}\right)$to hydrogen peroxide $\left(\mathrm{H}_{2} \mathrm{O}_{2}\right)$ and/or molecular oxygen. In humans, there are cytosolic (SOD1) and extracellular (SOD3) isoforms which utilize copper and zinc as cofactors while the mitochondrial (SOD2) isoform uses manganese as the cofactor. Manganese porphyrins $(\mathrm{MnP})$ are among the most prominent SOD mimics developed to date. MnPs are made up of a macrocyclic ring structure with manganese found at the center. Other SOD mimics also have similar structures but house a different metal at their center. Further detail of $\mathrm{MnP}$ alongside 
other prominent mimetics' synthesis, structure, kinetics, and potential therapeutic benefits has been extensively reviewed [112]. The therapeutic efficacy of MnPs is heavily dependent on the redox environment at the time of administration. For instance, $\mathrm{MnP}$ administration at the onset of diabetes inhibited oxidative damage in a rat model [113]. When administered after the onset of diabetes, however, the same MnP actually increased oxidative damage [114].

GC4419 is a promising new MnP-like SOD mimetic highly specific for reacting with $\mathrm{O}_{2}{ }^{\bullet-}$. GC4419 has been shown to rescue cell clonogenicity of both a SOD2-null human embryonic kidney cell line [115] and radiation or chemotherapy-treated primary human dermal fibroblasts [116]. Intravenous delivery of GC4419 is currently in a phase II clinical trial for alleviating radiation-induced oral mucositis in patients with head and neck cancer (NCT02508389). Galera Therapeutics Inc. is also assessing the tolerability and pharmacokinetics of another SOD mimetic, GC4711, given orally compared to intravenous GC4419 in healthy volunteers (NCT03099824). BMX-001 is a MnP currently in a phase I clinical trial for glioblastoma patients undergoing radiation therapy (NCT02655601). Additionally, a continuous infusion of MnP AEOL 10150 using a subcutaneously implanted osmotic pump was able to significantly reduce radiation-induced injury in a rat model [117] and has proven to be beneficial in a nonhuman primate radiation-induced injury model [118]. As of 2017, Aeolus Pharmaceuticals Inc. is working on moving AEOL 10150 into clinical trials. Of note, MnPs often can react with various species and moieties besides $\mathrm{O}_{2}{ }^{\bullet-}$ which expands their potential outside of being just a SOD mimetic but also complicates their utility.

4.4. Catalase Delivery. Catalase is an antioxidant enzyme that catalyzes the disproportionation of $\mathrm{H}_{2} \mathrm{O}_{2}$ to $\mathrm{O}_{2}$ and $\mathrm{H}_{2} \mathrm{O}$; it decreases neuroinflammation and attenuates neurodegeneration in the CNS.

An important component of many metabolic and inflammatory diseases of the CNS involves inflammation [119]. These include Alzheimer's and Parkinson's diseases (AD and PD) [120-122], stroke [123, 124], traumatic brain injury (TBI), multiple sclerosis (MS), age-related macular degeneration (AMD), prion disease, meningitis, encephalitis, human immunodeficiency virus- (HIV-) associated neurocognitive disorders [125, 126], epilepsy, brain cancer, lysosomal storage diseases $[127,128]$, obesity $[129,130]$, and even mental health disorders such as depression, autism, and schizophrenia. These diseases are often accompanied by the extensive recruitment of immunocytes. Such inflammatory activities are linked to microglial activation and its secretion of neurotoxic factors. These include ROS and RNS leading to oxidative stress and neuronal injuries [131-134]. Oxidative stress affects neuronal, astrocyte, and microglia function by inducing ion transport and calcium mobilization and activating apoptotic programs. Apoptosis and excitotoxicity are principal causes of mitochondrial-induced neuronal death. Therefore, the need for delivery of potent antioxidants, in particular, catalase to affected brain tissues cannot be overstated.
The administration of catalase has been shown to rescue the primary cultured cerebellar granule cells in in vitro models of PD $[135,136]$. Thus, addition of catalase to cerebellar granule cells treated with a toxin, 1-methyl-4phenyl-1,2,3,6-tetrahydropyridine (MPTP) that causes a severe and irreversible parkinsonian syndrome in humans and in nonhuman primates [137], resulted in enhancing their viability by $75 \%$ compared to the control cells. Regrettably, the blood-brain barrier (BBB) severely restricts the transport of this potent antioxidant to the brain. Although small lipophilic molecules ( $\mathrm{MW}<400 \mathrm{kDa}$ ) can cross the $\mathrm{BBB}$ in pharmacologically significant amounts, effective concentrations of lipid-insoluble drugs (polar molecules and small ions), as well as high molecular weight compounds (peptides, proteins, and nucleic acids), cannot be delivered to the CNS within the limits of clinical toxicity. The inability of most potent therapeutics to cross the $\mathrm{BBB}$ following systemic administration necessitates the need to develop unconventional, clinically applicable drug delivery systems for the treatment of brain disorders. Smart, biologically active vehicles are crucial to accomplishing this challenging task.

To this end, immunocytes that include mononuclear phagocytes (dendritic cells, monocytes, and macrophages), neutrophils, and lymphocytes can carry nanoformulated drugs as they readily home to disease sites. Using living cells as drug delivery vehicles, takes advantage of their natural carriage, storage, mobility, and secretory capacity. It offers several benefits over common drug administration regimens; these include targeted drug transport to disease sites, prolonged drug half-lives, time-controlled drug release, and diminished drug immunogenicity and cytotoxicity profiles. Thus, a cell-based delivery system to bring nanoformulated catalase to affected brain regions was developed [138, 139]. The system rests in the abilities of blood-borne macrophages to carry antioxidant proteins across the BBB to the inflamed tissues. Using inflammatory response cells enables targeted drug transport and prolonged circulation times [140], along with reductions in cell and tissue toxicities. In addition, these cells are capable of cell-to-cell transmission of drug-laden nanoparticles that improves their therapeutic outcomes.

One of the main obstacles in utilizing these cells is related to the fact that monocytes efficiently disintegrate and digest all entrapped foreign particles. Therefore, it is crucial to protect the activity of the drug inside this cell carrier [141]. To preclude macrophage-mediated enzyme degradation, catalase was packaged into a block ionomer complex with a cationic block copolymer, poly(ethyleneimine)poly(ethylene glycol) (PEI-PEG). Overall, the structure and composition of protective nanocontainers play a crucial role in the effectiveness of formulations for cell-based drug delivery systems. For example, a recent study by one of us indicates that structure of block copolymer used for catalase nanoformulation (nanozyme), affects its cytotoxicity, loading, and release capacities, as well as preservation of catalase enzymatic activity inside cell-carriers [142]. Bone marrowderived macrophages (BMM) carried significant amounts of catalase then slowly released the active enzyme over several days [138]. The enzyme released upon stimulation of nanozyme-loaded cell carriers decomposed microglial $\mathrm{H}_{2} \mathrm{O}_{2}$ 
produced upon nitrated alpha-synuclein or tumor necrosis factor alpha- (TNF- $\alpha$-) induced activation in vitro. A significant amount of catalase was detected in brains of mice after transfer of BMM loaded with nanoformulated catalase following MPTP intoxication. It was demonstrated that such nanozyme-loaded BMM injected into MPTPintoxicated mice reduce neuroinflammation and attenuate nigrostriatal degeneration [139]. This signified a neuroprotective effect of nanozyme-loaded monocytes in MPTPinduced neurodegeneration.

Another approach to targeted cell-mediated brain delivery of catalase is to utilize macrophages transfected ex vivo with a plasmid DNA (pDNA) encoding catalase [143]. Systemic administration of pretransfected macrophages produced month-long expression levels of catalase in the brain resulting in threefold reductions in inflammation and complete neuroprotection in mouse models of PD. This resulted in significant improvements in motor functions in PD mice. Mechanistic studies revealed that transfected macrophages secreted extracellular vesicles, exosomes, packed with catalase genetic material, pDNA and mRNA, active catalase, and NF- $\kappa \mathrm{B}$, a transcription factor involved in the encoded gene expression. Exosomes efficiently transfer their contents to contiguous neurons resulting in de novo protein synthesis in target cells. Thus, genetically modified macrophages serve as a highly efficient system for reproduction, packaging, and targeted gene and drug delivery to treat inflammatory and neurodegenerative disorders [143]. Of note, a proper differentiation of drug carriers into particular subtypes may further boost the therapeutic efficiency of cell-based drug formulations [144]. Alternatively, activated macrophages phenotype (M2) utilized in these studies did not promote further inflammation in the brain, resulting in a subtle, but statistically significant effect on neuronal regeneration and repair in vivo.

Even though this modality of antioxidant enzyme delivery has not moved to clinical trials yet, it is a promising approach to deliver redox-active enzymes in a targeted manner and to overcome several of the obstacles related to delivery of proteins and delivery to the CNS.

\section{Small Molecule Antioxidants}

Small (MW <250 kDA) molecule antioxidants have desirable pharmacokinetic properties able to exponentially enhance antioxidant defense by directly acting on signaling pathways [145]. Phenolic groups dominate this class but there are multiple other species with unique antioxidant properties [146]. In this section, we will discuss some of the most commonly used and already developed small molecule antioxidants and highlight emerging formulations (Figure 1).

5.1. Electrophiles. Electrophilic small molecules are potent activators of the nuclear factor erythroid 2-related factor 2 (Nrf2) pathway. Nrf2 is a transcription factor that induces the production of antioxidant and detoxification enzymes controlled by an enhancer sequence called the antioxidant response element/electrophile responsive element (ARE/ EpRE). The identification of $\mathrm{Nrf} 2$ as the critical transcription factor in this pathway was only recognized in 1997 [29]. This discovery triggered tremendous progress in understanding the increased efficacy of small molecule antioxidants in therapeutic applications. Under homeostatic conditions, Nrf2 is sequestered to the cytoplasm by the actin-bound inhibitor Kelch-like ECH-associated protein 1 (Keap1). Keap1 subjects Nrf2 to polyubiquitination and degradation via the proteasome. During redox imbalance, or if the cell is exposed to electrophilic small molecules, key cysteine residues on Keap1 are oxidized causing a conformational change that releases Nrf2. Under these conditions, Nrf2 is able to translocate to the nucleus where it forms heterodimers with Maf proteins and binds ARE/EpRE. Nrf2 binding to ARE/ EpRE results in transcription of cytoprotective enzymes such as catalase, glutathione S-transferase, $\mathrm{NAD}(\mathrm{P}) \mathrm{H}$ quinone oxidoreductase 1, SOD 1 , heme oxygenase 1 , and many more.

5.1.1. Sulforaphane. Sulforaphane (SFN) is an isothiocyanate metabolite found in cruciferous vegetables, such as broccoli, and is one of the most widely studied electrophilic Nrf2 inducers. The anticarcinogenic properties of broccoli were attributed to SFN when it was first identified as a phase II metabolic enzyme inducer in 1992 [147]. After the characterization of the Nrf2/Keap1 pathway, SFN was identified as a $\mathrm{Nrf} 2$ inducer further describing its potential in anticancer therapy [148]. Since then, oral administration of SFN has been shown to improve behavioral symptoms of young men with autism spectrum disorder [149] and is being further evaluated for this condition (NCT02561481, NCT02879110, and NCT02909959). SFN has also been shown to improve fasting glucose in obese patients with dysregulated type 2 diabetes [150] and is currently in a phase II clinical trial (NCT02801448). As a redox-based therapeutic, SFN is making headway in animal models of atherosclerosis. Angioplasty with stent placement is the most common surgical intervention for treating atherosclerosis or a stenotic vessel. A major complication following angioplasty is vessel reocclusion or restenosis. Currently, restenosis is best inhibited by chemotherapy-eluting stents, yet they create a favorable local environment for thrombosis [151]. Yoo et al. [152] showed that local application of SFN at the site of arterial injury inhibits restenosis in an angioplasty-injury rat model. This was attributed to the Nrf2-activating properties of SFN, which likely inhibits the phenotypic change in vascular smooth muscles that drives restenosis. Multiple other groups have since successfully inhibited restenosis using SFN in similar animal models $[153,154]$. One of us has been studying local delivery of other electrophiles such as cinnamic aldehyde as a therapy to inhibit restenosis. Development of a delivery vehicle that specifically targets the site of an atherosclerotic plaque could provide a novel antioxidant approach for treating vasculopathies and improving surgical outcomes and is the current focus of our lab.

5.1.2. Dimethyl Fumarate. Dimethyl fumarate (DMF) is an esterified fumaric acid that can inhibit NF- $\kappa \mathrm{B}$ activation [155]. DMF effectively increases relapsing-remitting multiple sclerosis patient quality of life when administered orally as 
a delayed-release conformation, termed BG00012 [156] (NCT00420212). DMF interacts with GSH under specific conditions in the bloodstream which limits this absorption route and bioavailability, justifying why recent studies mostly use limited and/or low doses of DMF [157]. New formulations of DMF or newly synthesized derivatives could improve the pharmacokinetics of this compound and provide useful new approaches.

5.1.3. Nitro-Oleic Acid. Nitro-oleic acid is one of the many nitrated fatty acids naturally present in human and animal tissues. Nitrated fatty acids result from ${ }^{\circ} \mathrm{NO}$-derived species reacting with unsaturated fatty acids resulting in ${ }^{\circ} \mathrm{NO}_{2}$ addition at a double bond [158]. Nitro-oleic acid has been shown to have cytoprotective properties through Nrf2 and PPAR $\gamma$ activation and NF- $\kappa \mathrm{B}$ inhibition [158]. CXA-10 is an orally administered 10-nitro-oleic-acid compound developed by Complexa Inc. CXA-10 has been trialed in five phase I clinical trials related to kidney injury as of 2017 (NCT02313064, NCT02127190, NCT02248051, NCT02460146, and NCT02547402) with differentiated safety in over 100 subjects reported as well as activation of target genes and inhibition of disease-related fibrotic and inflammatory biomarkers. Notably, the metabolic profile of patients in NCT02127190 has recently been characterized [159]. CXA-10 is set to enter phase II trials in 2018 for the treatment of pulmonary arterial hypertension and focal segmental glomerulosclerosis, two life-threatening diseases with a severely poor prognosis. These and future trials using nitrated lipids may yield effective redox-based therapies.

5.1.4. Synthetic Electrophiles. Recently, there has been a surge in development of ARE-/EpRE-inducing molecules. Such molecules include $\mathrm{N}$-iodoacetyl-N-biotinylhexylenediamine (IAB) which modifies Keap1 [160] but so far has a minimum effect on Nrf2 activation due to cytotoxicity and engagement with intracellular proteins [161]. Dai et al. [162] recently showed that several new formulations of Pyrazino[2,1-a]isoquinolin analogues, compounds originally designed for their antifungal properties [163], have potential as inducers of the Nrf2 pathway. Future studies using novel formulations may yield exciting therapeutics in the upcoming years. Moreover, testing new synthetic electrophilic compounds using novel platforms for targeted delivery could offer significant advances in redox medicine.

5.2. Nitric Oxide and Related Compounds. ${ }^{\bullet} \mathrm{NO}$ is a small nitrogen-centered free radical gas that can diffuse several cell diameters from its production site. As mentioned above, it is synthesized by nitric oxide synthases (NOS). It serves as a neurotransmitter involved in memory and learning, and as a signaling molecule controlling vascular tone, cell proliferation, and cell survival. During inflammation an inducible form of NOS (iNOS) produces large quantities of ${ }^{*} \mathrm{NO}$ involved in host protection against pathogens. Because of its role in vascular homeostasis, its potential therapeutic role in vascular disease has been extensively studied and is reviewed elsewhere [164]. Direct inhalation of ${ }^{\circ} \mathrm{NO}$ is the simplest way to deliver it. Inhaled ${ }^{\bullet} \mathrm{NO}$ has been clinically used to treat pulmonary hypertension and acute respiratory distress syndrome. However, a recent systematic review analyzing 14 different trials shows that even though inhaled nitric oxide improves oxygenation, there is no reduction in mortality [165]. On the other hand, inhalational ${ }^{\circ} \mathrm{NO}$ appears to be beneficial for respiratory failure in terms of infants after meta-analysis of 16 studies [166]. ${ }^{\circ} \mathrm{NO}$ reduced mortality and/or use of extracorporeal membrane oxygenation. Moreover, inhalational ${ }^{\circ} \mathrm{NO}$ reduces development of chronic lung disease and use of extracorporeal membrane oxygenation in newborns with persistent pulmonary hypertension [167]. Similarly, Miller et al. [168] conducted a randomized study in infants with pulmonary hypertension after congenital heart surgery. They found that inhalation of ${ }^{\bullet} \mathrm{NO}$ lessens the risk of pulmonary hypertensive crises and shortens postoperative recovery [168].

Since ${ }^{\circ} \mathrm{NO}$ is highly reactive, inhalational ${ }^{\circ} \mathrm{NO}$ is mostly a local intervention to the airways. When it comes to systemic administration, different strategies have been used to increase ${ }^{\circ} \mathrm{NO}$ : administration of its precursors L-arginine, use of ${ }^{\circ} \mathrm{NO}$ donors, or use of other ${ }^{\circ} \mathrm{NO}$ bioactive compounds such as nitrates, nitrite, or S-nitrosothiols. A systematic review in 2017 that included 5 completed clinical trials assessing the use of glyceryl trinitrate in patients with stroke concluded that there is no evidence to recommend use of this drug in stroke [169]. The amount of preclinical data suggesting a beneficial effect of increasing ${ }^{\circ} \mathrm{NO}$ for the treatment of vascular disease has not led to a successful clinical translation. Even though there are several attempts to increase ${ }^{\circ} \mathrm{NO}$ via systemic administration of L-arginine or nitric oxide donors, they have failed to improve vascular outcomes (reviewed in [164] and [170]). A large prospective multicenter, randomized trial studying the effect of ${ }^{\circ} \mathrm{NO}$ donors on restenosis after balloon angioplasty showed a modest improvement on angiographic restenosis but no differences in clinical outcomes [171]. These negative results highlight the issue of attempting to treat a localized ${ }^{\circ} \mathrm{NO}$ deficiency at sites of arterial disease via a systemic approach. Hence, numerous attempts to deliver bioactive ${ }^{\circledR} \mathrm{NO}$ locally aim at overcoming the problems with systemic delivery. Endolumenal delivery of ${ }^{\circ} \mathrm{NO}$ via a permeable balloon catheter inhibits restenosis in the rat carotid balloon injury model [172]. We have shown that an S-nitrosated nanofiber targeted to sites of arterial injury significantly inhibits restenosis in the rat balloon carotid injury model [173].

Further evidence that targeted or localized approaches result in successful clinical application of ${ }^{\circ} \mathrm{NO}$-based therapies is provided from fields that lend themselves to formulations for local delivery. One such field is dermatology, and the anti-inflammatory and antimicrobial properties of ${ }^{\circ} \mathrm{NO}$ show promise to treat acne vulgaris [174]. Results of a phase II clinical trial (NCT01844752) show that a topical formulation of ${ }^{\bullet} \mathrm{NO}$ decreases inflammatory and noninflammatory lesions in subjects with acne vulgaris [175].

5.3. Flavonoids. Flavonoids are a group of naturally occurring compounds found in many fruits and vegetables as well as beverages such as tea and wine. The flavonoid active compounds are secondary metabolites that have been proven 
beneficiary in protecting against atherosclerotic disease progression [176]. Flavonoids were initially identified for their direct scavenging properties but recent findings point out that the indirect antioxidant effects are of greater biological relevance and better support the use of these compounds as therapeutics [177]. Accordingly, flavonoids have been ascribed to anti-inflammatory, anticancer, and antithrombotic properties with dose-dependent effects [178].

5.3.1. Curcumin. Curcuma longa, turmeric, is the yellowpigmented spice commonly used in curries that is comprised of naturally occurring phenolic compounds called curcuminoids. Curcumin is the most abundant of the curcuminoids and is classified as a linear diarylheptanoid with multiple functional groups. In mice, curcumin has been shown to induce Nrf2 nuclear translocation and induction of ARE/ EpRE signaling [179]. Curcumin has been shown to inhibit gastric tumor growth by disrupting cellular bioenergetics [180] and to reduce the atherogenic and dyslipidemic panel in patients with chronic disease [181, 182]. Multiple studies show adjunct supplementation of curcumin with other active ingredients induces redox homeostasis in metabolic syndrome [183]. Of note, curcumin has been extensively pursued as a therapeutic with over $\$ 150$ million in federal funds linked to biomedical studies, yet no conclusive therapeutic effects in humans have been determined to date [184]. Nelson et al. [184] recently published an extensive review describing some considerations to explain the pitfalls of using curcumin. In general, the poor absorption of curcumin and limited abundance of the active compound may hinder its therapeutic potential as a systemic agent. Furthermore, they classify curcumin as a pan-assay interference compound which may show activity in an assay by interfering with the readout rather than by the specific compound/ target interaction the assay aims to assess. Nevertheless, because of its lipophilic characteristics, curcumin could still be considered a good agent for synergic localized or targeted therapy if better formulations arise. Indeed, nanoparticleencapsulated curcumin has been shown to have antimicrobial properties and to promote wound healing in an in vivo murine wound model [185].

5.3.2. Quercetin. Quercetin is a polyphenolic, pigmented flavonoid found in capers and onions that acts as an ROS scavenger. Quercetin has been proposed to have antioxidant effects in inducible vascular models of disease [186, 187], while also exhibiting anti-inflammatory and antineoplastic properties in several other models [188-190]. Unfortunately, most flavonoids are not readily absorbed by the human intestine which severely limits the bioavailability and overall therapeutic potential of quercetin [191]. It has failed to exhibit the anticipated preventative effects on serum phospholipids in healthy subjects as a supplement over an 8 -week period [192]. Also, no significant changes in endothelial function or ${ }^{\circ} \mathrm{NO}$ production were reported after 50-400 mg doses of water-dissolved quercetin extract were given to healthy subjects [193] (ACTRN12615001338550). It has been reported that a food matrix, as in onion powder rather than extract, significantly increases the bioavailability of quercetin in animals and humans [194]. Burak et al. [195] recently showed that the use of concomitant onion skin extract, instead of quercetin dehydrate alone, significantly increased the oral bioavailability of quercetin in healthy subjects. Extracting quercetin during food processing may be the factor limiting bioavailability of this flavonoid. As such, combinatorial therapy with other antioxidants, as has recently been trialed [196], may enhance quercetin delivery and overall benefit.

5.3.3. Resveratrol. Resveratrol is a natural phenol found in berries. It is the most studied flavonoid in scientific research and has the potential to induce Sirtuin-1 activity [197] and modulate Nrf2 [198] and NF- $\kappa \mathrm{B}$ [199]. In vitro studies indicate anti-inflammatory effects from resveratrol in multiple cell lines [200, 201]. In human keratinocytes, it has been shown to reduce $\mathrm{H}_{2} \mathrm{O}_{2}$-induced production of ROS [202]. It also has proven preventive antioxidant therapeutic effects in multiple animal injury models [203-205]. In chickens, resveratrol induces redox balance via heat shock protein regulation in immuno-competent tissues [206]. In clinical studies, oral supplementation in adult smokers significantly decreased acute phase markers and triglycerides but did not alter chronic disease markers, weight, and blood pressure [207]. Topical application of resveratrol and vitamin E increased skin pigmentation and elasticity by altering heme oxygenase 1 and other collagen-specific targeting genes [208]. Orally administered resveratrol reduced cardiovascular disease risk in hypercholesterolemia patients and also increased serum vitamin E levels [209]. Apostolidou et al. [209] highlight the synergistic properties of resveratrol and vitamin $\mathrm{E}$ in decreasing cardiovascular disease risk. This illustrates the great potential that flavonoids, specifically resveratrol, might have as a joint therapy with other antioxidant molecules.

\subsection{Thiol Molecules}

5.4.1. Glutathione. Glutathione (GSH) is a nonprotein, tripeptide thiol and one of the most abundant antioxidants in the body. In its reduced form, GSH is integral for cellular metabolism and maintaining cellular redox homeostasis. Work done by Mischley et al. [210] suggested that intranasal delivery may be able to augment GSH levels within the nervous system of patients with Parkinson's disease. In a follow-up phase II trial, however, there was no significant improvement in motor function from intranasal GSH delivery compared to the placebo [211]. In 2015, Schmitt et al. [212] showed that sublingual GSH was absorbed more effectively than oral supplementation by bypassing hepatic metabolism, potentially revealing a compelling new delivery approach. Several clinical trials assessing the benefit of oral GSH delivery are currently underway for growth improvement in children with cystic fibrosis (NCT03020719) and overall health of adults with a history of malnutrition (NCT03166371). Future work will dictate whether the therapeutic benefits of GSH can be through isolated administration or will continue to rely on intracellular upregulation by exogenous agents. 
5.4.2. N-Acetylcysteine. $\mathrm{N}$-acetylcysteine (NAC) is a prodrug thiol and precursor for cysteine and GSH. NAC treatment has been promising in in vitro [213] and in vivo [214] models but has fallen short in clinical trials similarly to most other antioxidants. NAC was ineffective in randomized clinical studies of arterial disease [215] and in attenuating nephrotoxicity [216]. Kazemi et al. [217] found no association from a high dose of prophylactic NAC given orally before and after surgery in preventing postoperative atrial fibrillation. A clinical trial evaluating NAC administered with amiodarone, which helps regulate heart rhythm, in preventing atrial fibrillation after thoracic surgery is currently in phase III (NCT02750319). Synergic NAC administration has been promising in treating infection [218] and reflux disease [219]. Trials using NAC with L-carnitine for polycystic ovary syndrome (NCT03164421) and with the drug minocycline for the treatment of bipolar depression (NCT02719392) are currently underway. As of 2017, there are over 70 other ongoing clinical trials using NAC as a sole therapeutic or together with other antioxidant molecules or drugs which will broaden our understanding of this unique prodrug.

\subsection{Other Scavenging Molecules}

5.5.1. Coenzyme Q10 and MitoQ10. Coenzyme Q10 (CoQ10) is a lipid-soluble ubiquinol antioxidant with high functionality in the Golgi apparatus and endoplasmic reticulum [220]. CoQ10 has been shown to reduce oxidative stress by modulating UBIAD1 and eNOS enzymatic activity in cardiovascular tissues [221]. A research group from Linköping University in Sweden has published multiple papers using oral administration of CoQ10 in clinical studies. The results show a direct effect on serum selenium levels which corresponds with decreased cardiovascular mortality rate in elderly patients [222]. CoQ10 in joint administration with selenium modified over 100 different microRNA expression levels in healthy elderly patients [223]. Lastly, the joint administration with selenium for 4 years increased insulinlike growth factor-1, which has implications of antiinflammatory and antioxidative effects, further explaining the observed reduction in cardiovascular mortality in these trials [224]. Yet, a $300 \mathrm{mg}$ oral dose of CoQ10 12 hours postprocedure did not reduce periprocedural myocardial injury in patients with elective percutaneous coronary interventions but did decrease C-reactive protein [225]. MitoQ10 is a 3rd generation derivate of $\mathrm{CoQ} 10$ that has an added positive charge with direct targeting for the mitochondria. Even though this approach does not target a specific organ or tissue, it directs the redox intervention to a specific organelle. MitoQ10 administered in drinking water jointly with Losartan prevented hypertensive disease and consequent rat myocardial hypertrophy [226]. In a clinical trial, orally administered MitoQ10 showed no therapeutic benefit as a Parkinson's disease-modifying therapy [227]. MitoQ10 is currently in clinical trials for improving physiological function of middle-aged and older adults (NCT02597023), attenuating chronic kidney disease (NCT02364648), and reducing fatigue experienced by patients with multiple sclerosis
(NCT03166800). The benefits of these two therapeutics appear yet to come, especially for MitoQ10 as it advances into promising clinical trials.

5.5.2. Ebselen. Ebselen is a synthetic selenoorganic molecule with antioxidant, anti-inflammatory, antimicrobial, and antifungal properties. This molecule is capable of catalytically scavenging hydrogen peroxide and organic hydroperoxides, at the expense of cellular thiols, thus mimicking glutathione peroxidase [228]. Additionally, ebselen can react with $\mathrm{ONOO}^{-}\left(\mathrm{k}=10^{6} \mathrm{M}^{-1} \mathrm{~s}^{-1}\right)$ providing another possible mechanism of redox modulation [229]. Moreover, the ability of ebselen to react with cellular thiols makes ebselen a weak electrophile capable of activating Nrf2 [230]. SPI-1005 is an oral formulation of ebselen developed by Sound Pharmaceuticals Inc. that has undergone phase I trials for hearing loss (NCT01452607) and Meniere's disease (NCT02603081) and phase II trials for preventing noise-induced temporary auditory threshold shifts (NCT01444846) [231]. Currently, ebselen is in phase II trials to prevent ototoxicity (NCT02819856), as well as noise-induced (NCT02779192) and chemotherapy-induced (NCT01451853) hearing loss. Preclinical evidence suggested that ebselen improves insulin secretion and pancreatic islet viability in murine models of diabetes $[232,233]$; however, ebselen failed to improve glycemia and vascular function in a small clinical trial with diabetic patients [234]. Importantly, this trial measured redox markers and showed that the ebselen dose and regimen used did not reduce any systemic markers of oxidative stress, suggesting that redox regulation was not achieved. The failure of this trial should not be taken to imply that redox imbalance is not at the core of the disease. Rather, as the redox state was not altered, this suggests that a wrong dose, improper administration route, or perhaps even the wrong redox-active molecule was used. Ongoing work with different formulations of selenoorganic molecules [235] may yield new and interesting therapeutics.

5.5.3. Edaravone. Edaravone is a synthetic reactive species scavenging antioxidant previously named MCI-186. Edaravone has been reported to specifically quench hydroxyl radicals, thus preventing lipid peroxidation, and has been used for the treatment of ischemia-reperfusion injury in Japan for more than a decade [236]. Edaravone was rebranded as Radicava in 2017 after its approval by the U.S. Food and Drug Administration (FDA) for the treatment of amyotrophic lateral sclerosis (ALS) [237], a rare neurodegenerative disease that effects voluntary muscle movement. This designation was made after the conclusion of the final phase III trial in October of 2017 (NCT01492686). Radicava treatment significantly reduced the rate of disability progression experienced by patients with ALS. The FDA approval of an antioxidant molecule shows promise that identifying the proper disease and patient population for a given molecule can result in a successful drug campaign and, more importantly, in an effective redox-based therapy. 


\section{Conclusion}

A causal relationship linking redox dysfunction with disease would predict successful translation to the clinic of therapies aimed at restoring redox homeostasis. However, the complexity of cellular redox reactions continues to thwart the utility of antioxidants as effective therapeutics in disease prevention and treatment. The first trials aimed at restoring redox homeostasis utilized antioxidants for their direct scavenging and redox cycling properties but were largely unsuccessful. Current evidence suggests that using molecules to upregulate endogenous antioxidant enzyme expression can have useful therapeutic benefits. Likewise, inhibition of ROS/RNS producing enzymes or inhibiting pathways that promote excess ROS/RNS generation could ultimately yield a greater efficacy than attempting to scavenge these species directly. Early failures of redox-active molecules in clinical trials may reflect the wrong choice of therapeutic, the wrong dose, or wrong selection of a patient population that would benefit the most from the intervention. Not accounting for these possibilities might lead to the conclusion that redox dysfunction is not part of the disease etiology. Importantly, few studies actually assess the effect of the redox intervention on redox biomarkers. If an antioxidant fails to improve primary outcomes, it is important to know if it actually affects redox markers. If the intervention does not improve redox status, then it is likely that the selection of drug, dose, or route of administration was not ideal. This issue does not have a clear solution since there is not a consensus as to what biomarkers to use when assessing redox function in vivo. Having some evidence that the tested drug actually improves redox homeostasis, however, allows for the identification of a subset of patients that are more likely to benefit from the redox intervention. For example, the use of tirapazamine, a reductively activated drug to potentiate chemotherapy in patients with squamous cell carcinoma, showed a promising significant effect in patients with hypoxic tumors [238]. However, in a large phase III trial without selection for hypoxia, addition of tirapazamine to chemoradiotherapy showed no improvement in outcomes [239]. This highlights the need to identify the patient population that is most likely to benefit from the intervention. Failure to identify this subpopulation could dilute the patient pool potentially masking beneficial effects. Similarly, the example shows the importance of measuring the specific conditions related to the expected mechanism of action. Current studies address several of these issues. Importantly, many successful clinical trials have exploited local delivery or a targeted effect to specific cells. The realization that local and targeted drug delivery could directly address the problem of systemic effect of redox therapies opens a new and exciting avenue for translational redox research. As the drug delivery field develops new and better ways to precisely target therapeutic payloads to tissue sites, we can specifically address local redox dysfunction.

\section{Conflicts of Interest}

The authors declare that there are no conflicts of interest regarding the publication of this review.

\section{Acknowledgments}

The authors thank Ines Dr. Batinic-Haberle for assistance with the Superoxide Dismutase Mimetics and Ms. Danielle Berlin for comments on improving this manuscript. Nicholas E. Buglak is supported by a training grant from the NIEHS (T32ES007126). Edward S. M. Bahnson is a KL2 scholar partially supported by the UNC Clinical and Translational Science Award-K12 Scholars Program (KL2KL2TR00110903 PI-Buse). Edward S. M. Bahnson is also supported by institutional start-up funds and a Nutrition Obesity Research Center (NORC) Pilot and Feasibility Grant (P30DK056350) from the University of North Carolina at Chapel Hill.

\section{References}

[1] D. P. Jones, "Redefining oxidative stress," Antioxidants \& Redox Signaling, vol. 8, no. 9-10, pp. 1865-1879, 2006.

[2] B. Halliwell, "Free radicals, proteins and DNA: oxidative damage versus redox regulation," Biochemical Society Transactions, vol. 24, no. 4, pp. 1023-1027, 1996.

[3] S. P. Faux, T. Tai, D. Thorne, Y. Xu, D. Breheny, and M. Gaca, "The role of oxidative stress in the biological responses of lung epithelial cells to cigarette smoke," Biomarkers, vol. 14, Supplement 1, pp. 90-96, 2009.

[4] N. Li, M. Hao, R. F. Phalen, W. C. Hinds, and A. E. Nel, "Particulate air pollutants and asthma. A paradigm for the role of oxidative stress in PM-induced adverse health effects," Clinical Immunology, vol. 109, no. 3, pp. 250-265, 2003.

[5] R. M. Babadjouni, D. M. Hodis, R. Radwanski et al., "Clinical effects of air pollution on the central nervous system; a review," Journal of Clinical Neuroscience, vol. 43, pp. 1624, 2017.

[6] J. D'Orazio, S. Jarrett, A. Amaro-Ortiz, and T. Scott, "UV radiation and the skin," International Journal of Molecular Sciences, vol. 14, no. 6, pp. 12222-12248, 2013.

[7] V. M. Costa, F. Carvalho, J. A. Duarte, L. Bastos Mde, and F. Remiao, "The heart as a target for xenobiotic toxicity: the cardiac susceptibility to oxidative stress," Chemical Research in Toxicology, vol. 26, no. 9, pp. 1285-1311, 2013.

[8] M. Galicia-Moreno and G. Gutierrez-Reyes, "The role of oxidative stress in the development of alcoholic liver disease," Revista de Gastroenterología de México, vol. 79, no. 2, pp. 135-144, 2014.

[9] A. Barzilai and K. Yamamoto, "DNA damage responses to oxidative stress," DNA Repair, vol. 3, no. 8-9, pp. 1109$1115,2004$.

[10] A. Ayala, M. F. Munoz, and S. Arguelles, "Lipid peroxidation: production, metabolism, and signaling mechanisms of malondialdehyde and 4-hydroxy-2-nonenal," Oxidative Medicine and Cellular Longevity, vol. 2014, Article ID 360438, 31 pages, 2014.

[11] H. M. Stringfellow, M. R. Jones, M. C. Green, A. K. Wilson, and J. S. Francisco, "Selectivity in ROS-induced peptide backbone bond cleavage," The Journal of Physical Chemistry A, vol. 118, no. 48, pp. 11399-11404, 2014.

[12] V. Cecarini, J. Gee, E. Fioretti et al., "Protein oxidation and cellular homeostasis: emphasis on metabolism," Biochimica et Biophysica Acta (BBA) - Molecular Cell Research, vol. 1773, no. 2, pp. 93-104, 2007. 
[13] B. Uttara, A. V. Singh, P. Zamboni, and R. T. Mahajan, "Oxidative stress and neurodegenerative diseases: a review of upstream and downstream antioxidant therapeutic options," Current Neuropharmacology, vol. 7, no. 1, pp. 65-74, 2009.

[14] H. N. Siti, Y. Kamisah, and J. Kamsiah, "The role of oxidative stress, antioxidants and vascular inflammation in cardiovascular disease (a review)," Vascular Pharmacology, vol. 71, pp. 40-56, 2015.

[15] M. Nishikimi, R. Fukuyama, S. Minoshima, N. Shimizu, and K. Yagi, "Cloning and chromosomal mapping of the human nonfunctional gene for L-gulono-gamma-lactone oxidase, the enzyme for L-ascorbic acid biosynthesis missing in man," The Journal of Biological Chemistry, vol. 269, no. 18, pp. 13685-13688, 1994.

[16] R. Figueroa-Mendez and S. Rivas-Arancibia, "Vitamin C in health and disease: its role in the metabolism of cells and redox state in the brain," Frontiers in Physiology, vol. 6, p. 397, 2015.

[17] M. G. Traber and J. F. Stevens, "Vitamins C and E: beneficial effects from a mechanistic perspective," Free Radical Biology \& Medicine, vol. 51, no. 5, pp. 1000-1013, 2011.

[18] J. D. Schoenfeld, Z. A. Sibenaller, K. A. Mapuskar et al., "O $2^{-}$and $\mathrm{H}_{2} \mathrm{O}_{2}$ 'mediated disruption of $\mathrm{Fe}$ metabolism causes the differential susceptibility of NSCLC and GBM cancer cells to pharmacological ascorbate," Cancer Cell, vol. 31, no. 4, pp. 487-500.e8, 2017.

[19] D. J. Lane, S. Chikhani, V. Richardson, and D. R. Richardson, "Transferrin iron uptake is stimulated by ascorbate via an intracellular reductive mechanism," Biochimica et Biophysica Acta (BBA) - Molecular Cell Research, vol. 1833, no. 6, pp. 1527-1541, 2013.

[20] J. Du, S. M. Martin, M. Levine et al., "Mechanisms of ascorbate-induced cytotoxicity in pancreatic cancer," Clinical Cancer Research, vol. 16, no. 2, pp. 509-520, 2010.

[21] S. J. Padayatty, H. Sun, Y. Wang et al., "Vitamin C pharmacokinetics: implications for oral and intravenous use," Annals of Internal Medicine, vol. 140, no. 7, pp. 533-537, 2004.

[22] J. Verrax and P. B. Calderon, "Pharmacologic concentrations of ascorbate are achieved by parenteral administration and exhibit antitumoral effects," Free Radical Biology \& Medicine, vol. 47, no. 1, pp. 32-40, 2009.

[23] J. L. Welsh, B. A. Wagner, T. J. van’t Erve et al., "Pharmacological ascorbate with gemcitabine for the control of metastatic and node-positive pancreatic cancer (PACMAN): results from a phase I clinical trial," Cancer Chemotherapy and Pharmacology, vol. 71, no. 3, pp. 765-775, 2013.

[24] M. G. Traber and J. Atkinson, "Vitamin E, antioxidant and nothing more," Free Radical Biology \& Medicine, vol. 43, no. 1, pp. 4-15, 2007.

[25] D. Li, S. Devaraj, C. Fuller, R. Bucala, and I. Jialal, "Effect of alpha-tocopherol on LDL oxidation and glycation: in vitro and in vivo studies," Journal of Lipid Research, vol. 37, no. 9, pp. 1978-1986, 1996.

[26] P. Bozaykut, B. Karademir, B. Yazgan et al., "Effects of vitamin $\mathrm{E}$ on peroxisome proliferator-activated receptor $\gamma$ and nuclear factor-erythroid 2-related factor 2 in hypercholesterolemia-induced atherosclerosis," Free Radical Biology \& Medicine, vol. 70, pp. 174-181, 2014.

[27] F. Tang, M. Lu, S. Zhang et al., "Vitamin E conditionally inhibits atherosclerosis in ApoE knockout mice by anti- oxidation and regulation of vasculature gene expressions," Lipids, vol. 49, no. 12, pp. 1215-1223, 2014.

[28] C. Suarna, B. J. Wu, K. Choy et al., "Protective effect of vitamin $\mathrm{E}$ supplements on experimental atherosclerosis is modest and depends on preexisting vitamin E deficiency," Free Radical Biology \& Medicine, vol. 41, no. 5, pp. 722730, 2006.

[29] K. Itoh, T. Chiba, S. Takahashi et al., "An Nrf2/small Maf heterodimer mediates the induction of phase II detoxifying enzyme genes through antioxidant response elements," Biochemical and Biophysical Research Communications, vol. 236, no. 2, pp. 313-322, 1997.

[30] J. D. Hayes, J. U. Flanagan, and I. R. Jowsey, "Glutathione transferases," Annual Review of Pharmacology and Toxicology, vol. 45, no. 1, pp. 51-88, 2005.

[31] I. Bellezza, A. Tucci, F. Galli et al., "Inhibition of NF- $\kappa$ B nuclear translocation via HO-1 activation underlies alphatocopheryl succinate toxicity," The Journal of Nutritional Biochemistry, vol. 23, no. 12, pp. 1583-1591, 2012.

[32] Z. Feng, Z. Liu, X. Li et al., " $\alpha$-Tocopherol is an effective phase II enzyme inducer: protective effects on acrolein-induced oxidative stress and mitochondrial dysfunction in human retinal pigment epithelial cells," The Journal of Nutritional Biochemistry, vol. 21, no. 12, pp. 1222-1231, 2010.

[33] R. Dworski, W. Han, T. S. Blackwell, A. Hoskins, and M. L. Freeman, "Vitamin E prevents NRF2 suppression by allergens in asthmatic alveolar macrophages in vivo," Free Radical Biology \& Medicine, vol. 51, no. 2, pp. 516-521, 2011.

[34] J. H. Pan, L. Feng, W. D. Jiang et al., "Vitamin E deficiency depressed fish growth, disease resistance, and the immunity and structural integrity of immune organs in grass carp (Ctenopharyngodon idella): Referring to NF- $\kappa \mathrm{B}$, TOR and Nrf2 signaling," Fish \& Shellfish Immunology, vol. 60, pp. 219-236, 2017.

[35] M. Fidaleo, F. Fanelli, M. P. Ceru, and S. Moreno, "Neuroprotective properties of peroxisome proliferator-activated receptor alpha (PPAR $\alpha$ ) and its lipid ligands," Current Medicinal Chemistry, vol. 21, no. 24, pp. 2803-2821, 2014.

[36] S. P. Lakshmi, A. T. Reddy, A. Banno, and R. C. Reddy, "PPAR agonists for the prevention and treatment of lung cancer," PPAR Research, vol. 2017, Article ID 8252796, 8 pages, 2017.

[37] M. Chandra, S. Miriyala, and M. Panchatcharam, "PPAR $\gamma$ and its role in cardiovascular diseases," PPAR Research, vol. 2017, Article ID 6404638, 10 pages, 2017.

[38] N. G. Stephens, A. Parsons, P. M. Schofield, F. Kelly, K. Cheeseman, and M. J. Mitchinson, "Randomised controlled trial of vitamin $\mathrm{E}$ in patients with coronary disease: Cambridge Heart Antioxidant Study (CHAOS)," The Lancet, vol. 347, no. 9004, pp. 781-786, 1996.

[39] Heart outcomes prevention evaluation study investigators, S. Yusuf, G. Dagenais, J. Pogue, J. Bosch, and P. Sleight, "Vitamin E supplementation and cardiovascular events in high-risk patients," The New England Journal of Medicine, vol. 342, no. 3, pp. 154-160, 2000.

[40] L. J. Roberts 2nd, J. A. Oates, M. F. Linton et al., "The relationship between dose of vitamin $\mathrm{E}$ and suppression of oxidative stress in humans," Free Radical Biology \& Medicine, vol. 43, no. 10, pp. 1388-1393, 2007.

[41] U. Milman, S. Blum, C. Shapira et al., "Vitamin E supplementation reduces cardiovascular events in a subgroup of middle- 
aged individuals with both type 2 diabetes mellitus and the haptoglobin 2-2 genotype: a prospective double-blinded clinical trial," Arteriosclerosis, Thrombosis, and Vascular Biology, vol. 28, no. 2, pp. 341-347, 2008.

[42] I. P. Chatziralli, G. Theodossiadis, P. Dimitriadis et al., "The effect of vitamin $\mathrm{E}$ on oxidative stress indicated by serum malondialdehyde in insulin-dependent type 2 diabetes mellitus patients with retinopathy," The Open Ophthalmology Journal, vol. 11, no. 1, pp. 51-58, 2017.

[43] M. Rafraf, B. Bazyun, M. A. Sarabchian, A. Safaeiyan, B. P. Gargari, and E. Vitamin, "Improves serum paraoxonase-1 activity and some metabolic factors in patients with type 2 diabetes: no effects on nitrite/nitrate levels," Journal of the American College of Nutrition, vol. 35, no. 6, pp. 521528, 2016.

[44] A. Ahmadi, N. Mazooji, J. Roozbeh, Z. Mazloom, and J. Hasanzade, "Effect of alpha-lipoic acid and vitamin E supplementation on oxidative stress, inflammation, and malnutrition in hemodialysis patients," Iranian Journal of Kidney Diseases, vol. 7, no. 6, pp. 461-467, 2013.

[45] E. B. Parisotto, T. R. Garlet, V. L. L. O. Cavalli et al., "Antioxidant intervention attenuates oxidative stress in children and teenagers with down syndrome," Research in Developmental Disabilities, vol. 35, no. 6, pp. 1228-1236, 2014.

[46] M. W. Dysken, M. Sano, S. Asthana et al., "Effect of vitamin E and memantine on functional decline in Alzheimer disease: the TEAM-AD VA cooperative randomized trial," JAMA, vol. 311, no. 1, pp. 33-44, 2014.

[47] D. Alias, J. Ruiz-Tovar, A. Moreno et al., "Effect of subcutaneous sterile vitamin $\mathrm{E}$ ointment on incisional surgical site infection after elective laparoscopic colorectal cancer surgery," Surgical Infections, vol. 18, no. 3, pp. 287-292, 2017.

[48] F. A. Moura, K. Q. de Andrade, J. C. Dos Santos, and M. O. Goulart, "Lipoic acid: its antioxidant and anti-inflammatory role and clinical applications," Current Topics in Medicinal Chemistry, vol. 15, no. 5, pp. 458-483, 2015.

[49] B. C. Scott, O. I. Aruoma, P. J. Evans et al., "Lipoic and dihydrolipoic acids as antioxidants. A critical evaluation," Free Radical Research, vol. 20, no. 2, pp. 119-133, 2009.

[50] L. Packer, E. H. Witt, and H. J. Tritschler, "Alpha-lipoic acid as a biological antioxidant," Free Radical Biology \& Medicine, vol. 19, no. 2, pp. 227-250, 1995.

[51] R. C. Eason, H. E. Archer, S. Akhtar, and C. J. Bailey, "Lipoic acid increases glucose uptake by skeletal muscles of obese-diabetic ob/ob mice," Diabetes, Obesity \& Metabolism, vol. 4, no. 1, pp. 29-35, 2002.

[52] A. Goraca, H. Huk-Kolega, P. Kleniewska, A. PiechotaPolanczyk, and B. Skibska, "Effects of lipoic acid on spleen oxidative stress after LPS administration," Pharmacological Reports, vol. 65, no. 1, pp. 179-186, 2013.

[53] M. C. Cimolai, V. Vanasco, T. Marchini, N. D. Magnani, P. Evelson, and S. Alvarez, " $\alpha$-Lipoic acid protects kidney from oxidative stress and mitochondrial dysfunction associated to inflammatory conditions," Food \& Function, vol. 5, no. 12, pp. 3143-3150, 2014.

[54] F. Mignini, C. Nasuti, D. Fedeli et al., "Protective effect of alpha-lipoic acid on cypermethrin-induced oxidative stress in Wistar rats," International Journal of Immunopathology and Pharmacology, vol. 26, no. 4, pp. 871-881, 2013.

[55] T. B. Moraes, C. E. D. Jacques, A. P. Rosa et al., "Role of catalase and superoxide dismutase activities on oxidative stress in the brain of a phenylketonuria animal model and the effect of lipoic acid," Cellular and Molecular Neurobiology, vol. 33, no. 2, pp. 253-260, 2013.

[56] Z. Ying, N. Kherada, B. Farrar et al., "Lipoic acid effects on established atherosclerosis," Life Sciences, vol. 86, no. 3-4, pp. 95-102, 2010.

[57] Y. Nakashima, E. W. Raines, A. S. Plump, J. L. Breslow, and R. Ross, "Upregulation of VCAM-1 and ICAM-1 at atherosclerosis-prone sites on the endothelium in the ApoE-deficient mouse," Arteriosclerosis, Thrombosis, and Vascular Biology, vol. 18, no. 5, pp. 842-851, 1998.

[58] K. Brand, S. Page, G. Rogler et al., "Activated transcription factor nuclear factor-kappa B is present in the atherosclerotic lesion," Journal of Clinical Investigation, vol. 97, no. 7, pp. 1715-1722, 1996.

[59] W. R. Lee, A. Kim, K. S. Kim et al., "Alpha-lipoic acid attenuates atherosclerotic lesions and inhibits proliferation of vascular smooth muscle cells through targeting of the Ras/MEK/ERK signaling pathway," Molecular Biology Reports, vol. 39, no. 6, pp. 6857-6866, 2012.

[60] D. Ziegler, C. G. Sohr, and J. Nourooz-Zadeh, "Oxidative stress and antioxidant defense in relation to the severity of diabetic polyneuropathy and cardiovascular autonomic neuropathy," Diabetes Care, vol. 27, no. 9, pp. 21782183, 2004.

[61] D. Ziegler, A. Ametov, A. Barinov et al., "Oral treatment with alpha-lipoic acid improves symptomatic diabetic polyneuropathy: the SYDNEY 2 trial," Diabetes Care, vol. 29, no. 11, pp. 2365-2370, 2006.

[62] H. Garcia-Alcala, C. I. Santos Vichido, S. Islas Macedo et al., "Treatment with $\alpha$-lipoic acid over 16 weeks in type 2 diabetic patients with symptomatic polyneuropathy who responded to initial 4-week high-dose loading," Journal of Diabetes Research, vol. 2015, Article ID 189857, 8 pages, 2015.

[63] D. Ziegler, P. A. Low, W. J. Litchy et al., "Efficacy and safety of antioxidant treatment with $\alpha$-lipoic acid over 4 years in diabetic polyneuropathy: the NATHAN 1 trial," Diabetes Care, vol. 34, no. 9, pp. 2054-2060, 2011.

[64] L. Turner-Stokes, A. Thu, H. Williams, R. Casey, H. Rose, and R. J. Siegert, "The neurological impairment scale: reliability and validity as a predictor of functional outcome in neurorehabilitation," Disability and Rehabilitation, vol. 36, no. 1, pp. 23-31, 2014.

[65] N. Papanas and D. Ziegler, "Efficacy of $\alpha$-lipoic acid in diabetic neuropathy," Expert Opinion on Pharmacotherapy, vol. 15, no. 18, pp. 2721-2731, 2014.

[66] H. H. Conaway, P. Henning, and U. H. Lerner, "Vitamin a metabolism, action, and role in skeletal homeostasis," Endocrine Reviews, vol. 34, no. 6, pp. 766-797, 2013.

[67] Z. Al Tanoury, A. Piskunov, and C. Rochette-Egly, "Vitamin A and retinoid signaling: genomic and nongenomic effects," Journal of Lipid Research, vol. 54, no. 7, pp. 1761-1775, 2013.

[68] C. C. Brown and R. J. Noelle, "Seeing through the dark: new insights into the immune regulatory functions of vitamin A," European Journal of Immunology, vol. 45, no. 5, pp. 1287-1295, 2015.

[69] P. Di Mascio, S. Kaiser, and H. Sies, "Lycopene as the most efficient biological carotenoid singlet oxygen quencher," Archives of Biochemistry and Biophysics, vol. 274, no. 2, pp. 532-538, 1989. 
[70] L. Tesoriere, M. Ciaccio, A. Bongiorno, A. Riccio, A. M. Pintaudi, and M. A. Livrea, "Antioxidant activity of alltrans-retinol in homogeneous solution and in phosphatidylcholine liposomes," Archives of Biochemistry and Biophysics, vol. 307, no. 1, pp. 217-223, 1993.

[71] R. Hubbard and G. Wald, "Cis-trans isomers of vitamin a and retinene in the rhodopsin system," The Journal of General Physiology, vol. 36, no. 2, pp. 269-315, 1952.

[72] M. E. Darvin, J. W. Fluhr, M. C. Meinke, L. Zastrow, W. Sterry, and J. Lademann, "Topical beta-carotene protects against infra-red-light-induced free radicals," Experimental Dermatology, vol. 20, no. 2, pp. 125-129, 2011.

[73] U. Heinrich, C. Gärtner, M. Wiebusch et al., "Supplementation with beta-carotene or a similar amount of mixed carotenoids protects humans from UV-induced erythema," The Journal of Nutrition, vol. 133, no. 1, pp. 98-101, 2003.

[74] R. Kafi, H. S. Kwak, W. E. Schumacher et al., "Improvement of naturally aged skin with vitamin a (retinol)," Archives of Dermatology, vol. 143, no. 5, pp. 606-612, 2007.

[75] S. Kang and J. J. Voorhees, "Photoaging therapy with topical tretinoin: an evidence-based analysis," Journal of the American Academy of Dermatology, vol. 39, no. 2, Supplement 2, pp. S55-S61, 1998.

[76] H. E. Baldwin, M. Nighland, C. Kendall, D. A. Mays, R. Grossman, and J. Newburger, "40 years of topical tretinoin use in review," Journal of Drugs in Dermatology, vol. 12, no. 6, pp. 638-642, 2013.

[77] E. Bagatin, L. R. S. Guadanhim, M. M. S. S. Enokihara et al., "Low-dose oral isotretinoin versus topical retinoic acid for photoaging: a randomized, comparative study," International Journal of Dermatology, vol. 53, no. 1, pp. 114-122, 2014.

[78] L. Beckenbach, J. M. Baron, H. F. Merk, H. Loffler, and P. M. Amann, "Retinoid treatment of skin diseases," European Journal of Dermatology, vol. 25, no. 5, pp. 384-391, 2015.

[79] R. S. Dassanayake, D. E. Cabelli, and N. E. Brasch, "Pulse radiolysis studies on the reaction of the reduced vitamin $B_{12}$ complex Cob(II)alamin with superoxide," ChemBioChem, vol. 14, no. 9, pp. 1081-1083, 2013.

[80] E. Suarez-Moreira, J. Yun, C. S. Birch, J. H. Williams, A. McCaddon, and N. E. Brasch, "Vitamin $\mathrm{B}_{12}$ and redox homeostasis: $\mathrm{Cob}(\mathrm{II})$ alamin reacts with superoxide at rates approaching superoxide dismutase (SOD)," Journal of the American Chemical Society, vol. 131, no. 42, pp. 1507815079, 2009.

[81] M. A. Flynn, W. Irvin, and G. Krause, "The effect of folate and cobalamin on osteoarthritic hands," Journal of the American College of Nutrition, vol. 13, no. 4, pp. 351-356, 1994.

[82] J. Guest, A. Bilgin, B. Hokin, T. A. Mori, K. D. Croft, and R. Grant, "Novel relationships between B12, folate and markers of inflammation, oxidative stress and $\mathrm{NAD}(\mathrm{H})$ levels, systemically and in the CNS of a healthy human cohort," Nutritional Neuroscience, vol. 18, no. 8, pp. 355364, 2015.

[83] E. S. Moreira, N. E. Brasch, and J. Yun, "Vitamin $B_{12}$ protects against superoxide-induced cell injury in human aortic endothelial cells," Free Radical Biology \& Medicine, vol. 51, no. 4, pp. 876-883, 2011.

[84] M. Y. Al-Maskari, M. I. Waly, A. Ali, Y. S. Al-Shuaibi, and A. Ouhtit, "Folate and vitamin B12 deficiency and hyperhomocysteinemia promote oxidative stress in adult type 2 diabetes," Nutrition, vol. 28, no. 7-8, pp. e23-e26, 2012.
[85] Y. J. Lee, M. Y. Wang, M. C. Lin, and P. T. Lin, "Associations between vitamin B-12 status and oxidative stress and inflammation in diabetic vegetarians and omnivores," Nutrients, vol. 8, no. 3, p. 118, 2016.

[86] U. Till, P. Röhl, A. Jentsch et al., "Decrease of carotid intimamedia thickness in patients at risk to cerebral ischemia after supplementation with folic acid, vitamins B6 and B12," Atherosclerosis, vol. 181, no. 1, pp. 131-135, 2005.

[87] F. F. Willems, W. R. Aengevaeren, G. H. Boers, H. J. Blom, and F. W. Verheugt, "Coronary endothelial function in hyperhomocysteinemia: improvement after treatment with folic acid and cobalamin in patients with coronary artery disease," Journal of the American College of Cardiology, vol. 40, no. 4, pp. 766-772, 2002.

[88] O. Bleie, S. Elin, M. Ueland Per et al., "Coronary blood flow in patients with stable coronary artery disease treated long term with folic acid and vitamin B12," Coronary Artery Disease, vol. 22, no. 4, pp. 270-278, 2011.

[89] R. Kaji, M. Kodama, A. Imamura et al., "Effect of ultrahigh-dose methylcobalamin on compound muscle action potentials in amyotrophic lateral sclerosis: a doubleblind controlled study," Muscle \& Nerve, vol. 21, no. 12, pp. 1775-1778, 1998.

[90] A. Macri, C. Scanarotti, A. M. Bassi et al., "Evaluation of oxidative stress levels in the conjunctival epithelium of patients with or without dry eye, and dry eye patients treated with preservative-free hyaluronic acid $0.15 \%$ and vitamin B12 eye drops," Graefe's Archive for Clinical and Experimental Ophthalmology, vol. 253, no. 3, pp. 425-430, 2015.

[91] H. Sies, "Oxidative stress: a concept in redox biology and medicine," Redox Biology, vol. 4, pp. 180-183, 2015.

[92] J. D. Lambeth, "NOX enzymes and the biology of reactive oxygen," Nature Reviews Immunology, vol. 4, no. 3, pp. 181-189, 2004.

[93] L. L. Hilenski, R. E. Clempus, M. T. Quinn, J. D. Lambeth, and K. K. Griendling, "Distinct subcellular localizations of Nox1 and Nox4 in vascular smooth muscle cells," Arteriosclerosis, Thrombosis, and Vascular Biology, vol. 24, no. 4, pp. 677-683, 2004.

[94] B. Diaz, G. Shani, I. Pass, D. Anderson, M. Quintavalle, and S. A. Courtneidge, "Tks5-dependent, nox-mediated generation of reactive oxygen species is necessary for invadopodia formation," Science Signaling, vol. 2, no. 88, article ra53, 2009.

[95] K. Bedard and K. H. Krause, "The NOX family of ROSgenerating NADPH oxidases: physiology and pathophysiology," Physiological Reviews, vol. 87, no. 1, pp. 245-313, 2007.

[96] J. Morry, W. Ngamcherdtrakul, and W. Yantasee, "Oxidative stress in cancer and fibrosis: opportunity for therapeutic intervention with antioxidant compounds, enzymes, and nanoparticles," Redox Biology, vol. 11, pp. 240-253, 2017.

[97] A. C. Little, A. Sulovari, K. Danyal, D. E. Heppner, D. J. Seward, and A. van der Vliet, "Paradoxical roles of dual oxidases in cancer biology," Free Radical Biology \& Medicine, vol. 110, pp. 117-132, 2017.

[98] Z. Nayernia, V. Jaquet, and K. H. Krause, "New insights on NOX enzymes in the central nervous system," Antioxidants \& Redox Signaling, vol. 20, no. 17, pp. 2815-2837, 2014.

[99] G. R. Drummond and C. G. Sobey, "Endothelial NADPH oxidases: which NOX to target in vascular disease?," Trends in Endocrinology and Metabolism, vol. 25, no. 9, pp. 452$463,2014$. 
[100] C. E. Holterman, N. C. Read, and C. R. Kennedy, "Nox and renal disease," Clinical Science, vol. 128, no. 8, pp. 465-481, 2015.

[101] C. Kleinschnitz, H. Grund, K. Wingler et al., "Post-stroke inhibition of induced NADPH oxidase type 4 prevents oxidative stress and neurodegeneration," PLoS Biology, vol. 8, no. 9, article e1000479, 2010.

[102] J. C. Jha, S. P. Gray, D. Barit et al., "Genetic targeting or pharmacologic inhibition of NADPH oxidase nox4 provides renoprotection in long-term diabetic nephropathy," Journal of the American Society of Nephrology, vol. 25, no. 6, pp. 1237-1254, 2014.

[103] S. H. Choi, M. Kim, H. J. Lee, E. H. Kim, C. H. Kim, and Y. J. Lee, "Effects of NOX1 on fibroblastic changes of endothelial cells in radiation induced pulmonary fibrosis," Molecular Medicine Reports, vol. 13, no. 5, pp. 4135-4142, 2016.

[104] N. K. Somanna, A. J. Valente, M. Krenz, W. P. Fay, P. Delafontaine, and B. Chandrasekar, "The Nox1/4 dual inhibitor GKT137831 or Nox4 knockdown inhibits angiotensin-II-induced adult mouse cardiac fibroblast proliferation and migration. AT1 physically associates with Nox4," Journal of Cellular Physiology, vol. 231, no. 5, pp. 1130-1141, 2016.

[105] S. P. Gray, J. C. Jha, K. Kennedy et al., "Combined NOX1/4 inhibition with GKT137831 in mice provides dose-dependent reno- and atheroprotection even in established micro- and macrovascular disease," Diabetologia, vol. 60, no. 5, pp. 927-937, 2017.

[106] S. Altenhofer, K. A. Radermacher, P. W. Kleikers, K. Wingler, and H. H. Schmidt, "Evolution of NADPH oxidase inhibitors: selectivity and mechanisms for target engagement," Antioxidants \& Redox Signaling, vol. 23, no. 5, pp. 406-427, 2015.

[107] N. Hecht, N. Terveer, C. Schollmayer, U. Holzgrabe, and L. Meinel, "Opening NADPH oxidase inhibitors for in vivo translation," European Journal of Pharmaceutics and Biopharmaceutics, vol. 115, pp. 206-217, 2017.

[108] U. Forstermann and W. C. Sessa, "Nitric oxide synthases: regulation and function," European Heart Journal, vol. 33, no. 7, pp. 829-837, 2012.

[109] A. Lopez, J. A. Lorente, J. Steingrub et al., "Multiple-center, randomized, placebo-controlled, double-blind study of the nitric oxide synthase inhibitor 546C88: effect on survival in patients with septic shock," Critical Care Medicine, vol. 32, no. 1, pp. 21-30, 2004.

[110] J. F. Stover, A. Belli, H. Boret et al., "Nitric oxide synthase inhibition with the antipterin VAS203 improves outcome in moderate and severe traumatic brain injury: a placebocontrolled randomized phase IIa trial (NOSTRA)," Journal of Neurotrauma, vol. 31, no. 19, pp. 1599-1606, 2014.

[111] K. Wada, K. Chatzipanteli, R. Busto, and W. D. Dietrich, "Role of nitric oxide in traumatic brain injury in the rat," Journal of Neurosurgery, vol. 89, no. 5, pp. 807-818, 1998.

[112] I. Batinic-Haberle, A. Tovmasyan, and I. Spasojevic, "An educational overview of the chemistry, biochemistry and therapeutic aspects of $\mathrm{Mn}$ porphyrins - from superoxide dismutation to $\mathrm{H} 2 \mathrm{O} 2$-driven pathways," Redox Biology, vol. 5, pp. 43-65, 2015.

[113] L. Benov and I. Batinic-Haberle, "A manganese porphyrin suppresses oxidative stress and extends the life span of streptozotocin-diabetic rats," Free Radical Research, vol. 39, no. 1, pp. 81-88, 2005.
[114] D. K. Ali, M. Oriowo, A. Tovmasyan, I. Batinic-Haberle, and L. Benov, "Late administration of Mn porphyrin-based SOD mimic enhances diabetic complications," Redox Biology, vol. 1, no. 1, pp. 457-466, 2013.

[115] K. Cramer-Morales, C. D. Heer, K. A. Mapuskar, and F. E. Domann, "SOD2 targeted gene editing by CRISPR/Cas9 yields human cells devoid of MnSOD," Free Radical Biology \& Medicine, vol. 89, pp. 379-386, 2015.

[116] K. A. Mapuskar, K. H. Flippo, J. D. Schoenfeld et al., "Mitochondrial superoxide increases age-associated susceptibility of human dermal fibroblasts to radiation and chemotherapy," Cancer Research, vol. 77, no. 18, pp. 5054-5067, 2017.

[117] Z. N. Rabbani, I. Batinic-Haberle, S. Poulton, M. S. Anscher, M. W. Dewhirst, and Z. Vujaskovic, "Long-term administration of a small molecular weight catalytic metalloporphyrin antioxidant, AEOL 10150, protects lungs from radiation-induced injury," International Journal of Radiation Oncology Biology Physics, vol. 63, no. 2, pp. S84S580, 2005.

[118] T. J. MacVittie, A. Gibbs, A. M. Farese et al., “AEOL 10150 mitigates radiation-induced lung injury in the nonhuman primate: morbidity and mortality are administration schedule-dependent," Radiation Research, vol. 187, no. 3, pp. 298-318, 2017.

[119] V. H. Perry, M. D. Bell, H. C. Brown, and M. K. Matyszak, "Inflammation in the nervous system," Current Opinion in Neurobiology, vol. 5, no. 5, pp. 636-641, 1995.

[120] R. D. Brinton, “A women's health issue: Alzheimer's disease and strategies for maintaining cognitive health," International Journal of Fertility and Women's Medicine, vol. 44, no. 4, pp. 174-185, 1999.

[121] I. Gozes, "Neuroprotective peptide drug delivery and development: potential new therapeutics," Trends in Neurosciences, vol. 24, no. 12, pp. 700-705, 2001.

[122] R. A. Kroll and E. A. Neuwelt, "Outwitting the blood-brain barrier for therapeutic purposes: osmotic opening and other means," Neurosurgery, vol. 42, no. 5, pp. 10831099, 1998.

[123] V. E. Koliatsos, R. E. Clatterbuck, H. J. W. Nauta et al., "Human nerve growth factor prevents degeneration of basal forebrain cholinergic neurons in primates," Annals of Neurology, vol. 30, no. 6, pp. 831-840, 1991.

[124] D. Dogrukol-Ak, W. A. Banks, N. Tuncel, and M. Tuncel, "Passage of vasoactive intestinal peptide across the bloodbrain barrier," Peptides, vol. 24, no. 3, pp. 437-444, 2003.

[125] A. Bachis and I. Mocchetti, "Brain-derived neurotrophic factor is neuroprotective against human immunodeficiency virus-1 envelope proteins," Annals of the New York Academy of Sciences, vol. 1053, no. 1, pp. 247-257, 2005.

[126] J. Ying Wang, F. Peruzzi, A. Lassak et al., "Neuroprotective effects of IGF-I against TNF $\alpha$-induced neuronal damage in HIV-associated dementia," Virology, vol. 305 , no. 1, pp. 6676, 2003.

[127] R. J. Desnick and E. H. Schuchman, "Enzyme replacement and enhancement therapies: lessons from lysosomal disorders," Nature Reviews Genetics, vol. 3, no. 12, pp. 954966, 2002.

[128] A. Urayama, J. H. Grubb, W. S. Sly, and W. A. Banks, "Developmentally regulated mannose 6-phosphate receptormediated transport of a lysosomal enzyme across the bloodbrain barrier," Proceedings of the National Academy of 
Sciences of the United States of America, vol. 101, no. 34, pp. 12658-12663, 2004.

[129] W. A. Banks and C. R. Lebel, "Strategies for the delivery of leptin to the CNS," Journal of Drug Targeting, vol. 10, no. 4, pp. 297-308, 2002.

[130] W. A. Banks, "Is obesity a disease of the blood-brain barrier? Physiological, pathological, and evolutionary considerations," Current Pharmaceutical Design, vol. 9, no. 10, pp. 801-809, 2003.

[131] P. L. McGeer, S. Itagaki, B. E. Boyes, and E. G. McGeer, "Reactive microglia are positive for HLA-DR in the substantia nigra of Parkinson's and Alzheimer's disease brains," Neurology, vol. 38, no. 8, pp. 1285-1291, 1988.

[132] J. Busciglio and B. A. Yankner, "Apoptosis and increased generation of reactive oxygen species in Down's syndrome neurons in vitro," Nature, vol. 378, no. 6559, pp. 776779, 1995.

[133] M. Ebadi, S. K. Srinivasan, and M. D. Baxi, "Oxidative stress and antioxidant therapy in Parkinson's disease," Progress in Neurobiology, vol. 48, no. 1, pp. 1-19, 1996.

[134] D. C. Wu, P. Teismann, K. Tieu et al., "NADPH oxidase mediates oxidative stress in the 1-methyl-4-phenyl-1,2,3,6tetrahydropyridine model of Parkinson's disease," Proceedings of the National Academy of Sciences of the United States of America, vol. 100, no. 10, pp. 6145-6150, 2003.

[135] K. N. Prasad, W. C. Cole, A. R. Hovland et al., "Multiple antioxidants in the prevention and treatment of neurodegenerative disease: analysis of biologic rationale," Current Opinion in Neurology, vol. 12, no. 6, pp. 761-770, 1999.

[136] R. A. Gonzalez-Polo, G. Soler, A. Rodriguezmartin, J. M. Moran, and J. M. Fuentes, "Protection against MPP+ neurotoxicity in cerebellar granule cells by antioxidants," Cell Biology International, vol. 28, no. 5, pp. 373-380, 2004.

[137] J. W. Langston and I. Irwin, "MPTP: current concepts and controversies," Clinical Neuropharmacology, vol. 9, no. 6, pp. 485-507, 1986.

[138] E. V. Batrakova, S. Li, A. D. Reynolds et al., "A macrophagenanozyme delivery system for Parkinson's disease," Bioconjugate Chemistry, vol. 18, no. 5, pp. 1498-1506, 2007.

[139] A. M. Brynskikh, Y. Zhao, R. L. Mosley et al., "Macrophage delivery of therapeutic nanozymes in a murine model of Parkinson's disease," Nanomedicine, vol. 5, no. 3, pp. 379396, 2010.

[140] Y. Zhao and M. J. . Haney, "Active targeted macrophagemediated delivery of catalase to affected brain regions in models of parkinson's disease," Journal of Nanomedicine \& Nanotechnology, vol. 01, no. S4, 2011.

[141] M. Fujiwara, J. D. Baldeschwieler, and R. H. Grubbs, "Receptor-mediated endocytosis of poly(acrylic acid)-conjugated liposomes by macrophages," Biochimica et Biophysica Acta (BBA) - Biomembranes, vol. 1278, no. 1, pp. 5967, 1996

[142] Y. Zhao, M. J. Haney, N. L. Klyachko et al., "Polyelectrolyte complex optimization for macrophage delivery of redox enzyme nanoparticles," Nanomedicine, vol. 6, no. 1, pp. 2542, 2011.

[143] M. J. Haney, Y. Zhao, E. B. Harrison et al., "Specific transfection of inflamed brain by macrophages: a new therapeutic strategy for neurodegenerative diseases," PLoS One, vol. 8, no. 4 , article e61852, 2013.
[144] N. L. Klyachko, M. J. Haney, Y. Zhao et al., "Macrophages offer a paradigm switch for CNS delivery of therapeutic proteins," Nanomedicine, vol. 9, no. 9, pp. 1403-1422, 2014.

[145] W. Hur and N. S. Gray, "Small molecule modulators of antioxidant response pathway," Current Opinion in Chemical Biology, vol. 15, no. 1, pp. 162-173, 2011.

[146] D. Sikazwe, A. Grillo, S. Ramsinghani, J. Davis, K. McQuiston, and S. Y. Ablordeppey, "Small diverse antioxidant functionalities for oxidative stress disease drug discovery," Mini Reviews in Medicinal Chemistry, vol. 12, no. 8, pp. 768774, 2012.

[147] Y. Zhang, P. Talalay, C. G. Cho, and G. H. Posner, "A major inducer of anticarcinogenic protective enzymes from broccoli: isolation and elucidation of structure," Proceedings of the National Academy of Sciences of the United States of America, vol. 89, no. 6, pp. 2399-2403, 1992.

[148] R. K. Thimmulappa, K. H. Mai, S. Srisuma, T. W. Kensler, M. Yamamoto, and S. Biswal, "Identification of Nrf2regulated genes induced by the chemopreventive agent sulforaphane by oligonucleotide microarray," Cancer Research, vol. 62, no. 18, pp. 5196-5203, 2002.

[149] K. Singh, S. L. Connors, E. A. Macklin et al., "Sulforaphane treatment of autism spectrum disorder (ASD)," Proceedings of the National Academy of Sciences of the Unites States of America, vol. 111, no. 43, pp. 1555015555, 2014.

[150] A. S. Axelsson, E. Tubbs, B. Mecham et al., "Sulforaphane reduces hepatic glucose production and improves glucose control in patients with type 2 diabetes," Science Translational Medicine, vol. 9, no. 394, artcile eaah4477, 2017.

[151] N. G. Kounis, I. Koniari, A. Roumeliotis et al., "Thrombotic responses to coronary stents, bioresorbable scaffolds and the Kounis hypersensitivity-associated acute thrombotic syndrome," Journal of Thoracic Disease, vol. 9, no. 4, pp. 1155-1164, 2017.

[152] S. H. Yoo, Y. Lim, S. J. Kim et al., "Sulforaphane inhibits PDGF-induced proliferation of rat aortic vascular smooth muscle cell by up-regulation of p53 leading to G1/S cell cycle arrest," Vascular Pharmacology, vol. 59, no. 1-2, pp. 44-51, 2013.

[153] N. M. Shawky, P. Pichavaram, G. S. G. Shehatou et al., "Sulforaphane improves dysregulated metabolic profile and inhibits leptin-induced VSMC proliferation: implications toward suppression of neointima formation after arterial injury in western diet-fed obese mice," The Journal of Nutritional Biochemistry, vol. 32, pp. 73-84, 2016.

[154] N. M. Shawky and L. Segar, "Sulforaphane inhibits plateletderived growth factor-induced vascular smooth muscle cell proliferation by targeting $\mathrm{mTOR} / \mathrm{p} 70$ S6kinase signaling independent of Nrf2 activation," Pharmacological Research, vol. 119, pp. 251-264, 2017.

[155] G. O. Gillard, B. Collette, J. Anderson et al., "DMF, but not other fumarates, inhibits NF- $\kappa$ B activity in vitro in an Nrf2-independent manner," Journal of Neuroimmunology, vol. 283, pp. 74-85, 2015.

[156] M. Kita, R. J. Fox, R. Gold et al., "Effects of delayed-release dimethyl fumarate (DMF) on health-related quality of life in patients with relapsing-remitting multiple sclerosis: an integrated analysis of the phase 3 DEFINE and CONFIRM studies," Clinical Therapeutics, vol. 36, no. 12, pp. 19581971, 2014. 
[157] N. M. de Bruin, K. Schmitz, S. Schiffmann et al., "Multiple rodent models and behavioral measures reveal unexpected responses to FTY720 and DMF in experimental autoimmune encephalomyelitis," Behavioural Brain Research, vol. 300, pp. 160-174, 2016.

[158] B. A. Freeman, P. R. Baker, F. J. Schopfer, S. R. Woodcock, A. Napolitano, and M. d'Ischia, "Nitro-fatty acid formation and signaling," Journal of Biological Chemistry, vol. 283, no. 23, pp. 15515-15519, 2008.

[159] S. R. Salvatore, D. A. Vitturi, M. Fazzari, D. K. Jorkasky, and F. J. Schopfer, "Evaluation of 10-nitro oleic acid bioelimination in rats and humans," Scientific Reports, vol. 7, no. 7, article 39900, 2017.

[160] F. Hong, K. R. Sekhar, M. L. Freeman, and D. C. Liebler, "Specific patterns of electrophile adduction trigger Keap1 ubiquitination and Nrf2 activation," Journal of Biological Chemistry, vol. 280, no. 36, pp. 31768-31775, 2005.

[161] D. Lin, S. Saleh, and D. C. Liebler, "Reversibility of covalent electrophile-protein adducts and chemical toxicity," Chemical Research in Toxicology, vol. 21, no. 12, pp. 23612369, 2008.

[162] H. Dai, Q. Jiao, T. Liu, Q. You, and Z. Jiang, "Development of novel Nrf2/ARE inducers bearing Pyrazino[2,1-a] isoquinolin scaffold with potent in vitro efficacy and enhanced physicochemical properties," Molecules, vol. 22, no. 9, 2017.

[163] H. Tang, C. H. Zheng, J. Zhu, B. Y. Fu, Y. J. Zhou, and J. G. Lv, "Design and synthesis of novel pyrazino[2,1-a]isoquinolin derivatives with potent antifungal activity," Archiv der Pharmazie, vol. 343, no. 6, pp. 360-366, 2010.

[164] K. M. Vural and M. Bayazit, "Nitric oxide: implications for vascular and endovascular surgery," European Journal of Vascular and Endovascular Surgery, vol. 22, no. 4, pp. 285293, 2001.

[165] F. Gebistorf, O. Karam, J. Wetterslev, and A. Afshari, "Inhaled nitric oxide for acute respiratory distress syndrome (ARDS) in children and adults," Cochrane Database of Systematic Reviews, no. 6, article CD002787, 2016.

[166] K. J. Barrington, N. Finer, T. Pennaforte, and G. Altit, "Nitric oxide for respiratory failure in infants born at or near term," Cochrane Database of Systematic Reviews, vol. 1, article CD000399, 2001.

[167] R. H. Clark, T. J. Kueser, M. W. Walker et al., "Low-dose nitric oxide therapy for persistent pulmonary hypertension of the newborn. Clinical inhaled nitric oxide research group," The New England Journal of Medicine, vol. 342, no. 7, pp. 469-474, 2000.

[168] O. I. Miller, S. F. Tang, A. Keech, N. B. Pigott, E. Beller, and D. S. Celermajer, "Inhaled nitric oxide and prevention of pulmonary hypertension after congenital heart surgery: a randomised double-blind study," The Lancet, vol. 356, no. 9240, pp. 1464-1469, 2000.

[169] P. M. Bath, K. Krishnan, and J. P. Appleton, "Nitric oxide donors (nitrates), L-arginine, or nitric oxide synthase inhibitors for acute stroke," Cochrane Database of Systematic Reviews, vol. 4, article CD000398, 2002.

[170] D. A. Popowich, V. Varu, and M. R. Kibbe, "Nitric oxide: what a vascular surgeon needs to know," Vascular, vol. 15, no. 6, pp. 324-335, 2007.

[171] J. M. Lablanche, G. Grollier, J. R. Lusson et al., "Effect of the direct nitric oxide donors linsidomine and molsidomine on angiographic restenosis after coronary balloon angioplasty.
The ACCORD study angioplastic coronaire corvasal diltiazem," Circulation, vol. 95, no. 1, pp. 83-89, 1997.

[172] G. E. Havelka, E. S. Moreira, M. P. Rodriguez et al., "Nitric oxide delivery via a permeable balloon catheter inhibits neointimal growth after arterial injury," The Journal of Surgical Research, vol. 180, no. 1, pp. 3542, 2013.

[173] E. S. Bahnson, H. A. Kassam, T. J. Moyer et al., "Targeted nitric oxide delivery by supramolecular nanofibers for the prevention of restenosis after arterial injury," Antioxidants \& Redox Signaling, vol. 24, no. 8, pp. 401418, 2016

[174] M. Qin, A. Landriscina, J. M. Rosen et al., "Nitric oxidereleasing nanoparticles prevent propionibacterium acnesinduced Inflammation by both clearing the organism and inhibiting microbial stimulation of the innate immune response," Journal of Investigative Dermatology, vol. 135, no. 11, pp. 2723-2731, 2015.

[175] H. Baldwin, D. Blanco, C. McKeever et al., "Results of a phase 2 efficacy and safety study with SB204, an investigational topical nitric oxide-releasing drug for the treatment of acne vulgaris," The Journal of Clinical and Aesthetic Dermatology, vol. 9, no. 8, pp. 12-18, 2016.

[176] C. Ferri and D. Grassi, "Antioxidants and beneficial microvascular effects: is this the remedy?," Hypertension, vol. 55, no. 6, pp. 1310-1311, 2010.

[177] H. Sies, "Polyphenols and health: update and perspectives," Archives of Biochemistry and Biophysics, vol. 501, no. 1, pp. 2-5, 2010.

[178] S. Wang, C. Yang, H. Tu et al., "Characterization and metabolic diversity of flavonoids in citrus species," Scientific Reports, vol. 7, no. 1, article 10549, 2017.

[179] Y. Nolvachai and P. J. Marriott, "GC for flavonoids analysis: past, current, and prospective trends," Journal of Separation Science, vol. 36, no. 1, pp. 20-36, 2013.

[180] L. Wang, X. Chen, Z. Du et al., "Curcumin suppresses gastric tumor cell growth via ROS-mediated DNA polymerase $\gamma$ depletion disrupting cellular bioenergetics," Journal of Experimental \& Clinical Cancer Research, vol. 36, no. 1, p. $47,2017$.

[181] M. Funamoto, Y. Sunagawa, Y. Katanasaka et al., "Highly absorptive curcumin reduces serum atherosclerotic lowdensity lipoprotein levels in patients with mild COPD," International Journal of Chronic Obstructive Pulmonary Disease, vol. 11, pp. 2029-2034, 2016.

[182] Y. Panahi, N. Khalili, E. Sahebi et al., "Curcuminoids modify lipid profile in type 2 diabetes mellitus: a randomized controlled trial," Complementary Therapies in Medicine, vol. 33, pp. 1-5, 2017.

[183] Y. Panahi, M. S. Hosseini, N. Khalili, E. Naimi, M. Majeed, and A. Sahebkar, "Antioxidant and anti-inflammatory effects of curcuminoid-piperine combination in subjects with metabolic syndrome: a randomized controlled trial and an updated meta-analysis," Clinical Nutrition, vol. 34, no. 6, pp. 1101-1108, 2015.

[184] K. M. Nelson, J. L. Dahlin, J. Bisson, J. Graham, G. F. Pauli, and M. A. Walters, "The essential medicinal chemistry of curcumin," Journal of Medicinal Chemistry, vol. 60, no. 5, pp. 1620-1637, 2017.

[185] A. E. Krausz, B. L. Adler, V. Cabral et al., "Curcumin-encapsulated nanoparticles as innovative antimicrobial and wound 
healing agent," Nanomedicine: Nanotechnology, Biology and Medicine, vol. 11, no. 1, pp. 195-206, 2015.

[186] I. Tinay, T. E. Sener, O. Cevik et al., "Antioxidant agent quercetin prevents impairment of bladder tissue contractility and apoptosis in a rat model of ischemia/reperfusion injury," LUTS: Lower Urinary Tract Symptoms, vol. 9, no. 2, pp. 117123, 2017.

[187] L. Xiao, L. Liu, X. Guo et al., "Quercetin attenuates high fat diet-induced atherosclerosis in apolipoprotein $\mathrm{E}$ knockout mice: a critical role of NADPH oxidase," Food and Chemical Toxicology, vol. 105, pp. 22-33, 2017.

[188] K. M. Doersch and M. K. Newell-Rogers, "The impact of quercetin on wound healing relates to changes in $\alpha \mathrm{V}$ and $\beta 1$ integrin expression," Experimental Biology and Medicine, vol. 242, no. 14, pp. 1424-1431, 2017.

[189] A. I. Abd El-Fattah, M. M. Fathy, Z. Y. Ali, A. E. A. El-Garawany, and E. K. Mohamed, "Enhanced therapeutic benefit of quercetin-loaded phytosome nanoparticles in ovariectomized rats," Chemico-Biological Interactions, vol. 271, pp. 30-38, 2017.

[190] N. M. Al-Rasheed, L. Fadda, H. A. Attia, I. A. Sharaf, A. M. Mohamed, and N. M. Al-Rasheed, "Pulmonary prophylactic impact of melatonin and/or quercetin: a novel therapy for inflammatory hypoxic stress in rats," Acta Pharmaceutica, vol. 67, no. 1, pp. 125-135, 2017.

[191] J. Terao, "Factors modulating bioavailability of quercetinrelated flavonoids and the consequences of their vascular function," Biochemical Pharmacology, vol. 139, pp. 1523, 2017.

[192] C. Burak, S. Wolffram, B. Zur et al., "Effects of the flavonol quercetin and $\alpha$-linolenic acid on n-3 PUFA status in metabolically healthy men and women: a randomised, double-blinded, placebo-controlled, crossover trial," The British Journal of Nutrition, vol. 117, no. 05, pp. 698711, 2017.

[193] N. P. Bondonno, C. P. Bondonno, L. Rich et al., "Acute effects of quercetin-3-O-glucoside on endothelial function and blood pressure: a randomized dose-response study," The American Journal of Clinical Nutrition, vol. 104, no. 1, pp. 97-103, 2016.

[194] Y. Kashino, K. Murota, N. Matsuda et al., "Effect of processed onions on the plasma concentration of quercetin in rats and humans," Journal of Food Science, vol. 80, no. 11, pp. H2597-H2602, 2015.

[195] C. Burak, V. Brüll, P. Langguth et al., "Higher plasma quercetin levels following oral administration of an onion skin extract compared with pure quercetin dihydrate in humans," European Journal of Nutrition, vol. 56, no. 1, pp. 343353, 2017.

[196] M. Torella, F. del Deo, A. Grimaldi et al., "Efficacy of an orally administered combination of hyaluronic acid, chondroitin sulfate, curcumin and quercetin for the prevention of recurrent urinary tract infections in postmenopausal women," European Journal of Obstetrics, Gynecology, and Reproductive Biology, vol. 207, pp. 125-128, 2016.

[197] F. J. Alcain and J. M. Villalba, "Sirtuin activators," Expert Opinion on Therapeutic Patents, vol. 19, no. 4, pp. 403414, 2009.

[198] S. Li, G. Zhao, L. Chen et al., "Resveratrol protects mice from paraquat-induced lung injury: the important role of SIRT1 and NRF2 antioxidant pathways," Molecular Medicine Reports, vol. 13, no. 2, pp. 1833-1838, 2016.
[199] Y. Tian, J. Ma, W. Wang et al., "Resveratrol supplement inhibited the NF- $\kappa \mathrm{B}$ inflammation pathway through activating AMPK $\alpha$-SIRT1 pathway in mice with fatty liver," Molecular and Cellular Biochemistry, vol. 422, no. 1-2, pp. 75-84, 2016.

[200] J. Schwager, N. Richard, F. Widmer, and D. Raederstorff, "Resveratrol distinctively modulates the inflammatory profiles of immune and endothelial cells," BMC Complementary and Alternative Medicine, vol. 17, no. 1, p. 309, 2017.

[201] M. R. Farag, M. Alagawany, and V. Tufarelli, "In vitro antioxidant activities of resveratrol, cinnamaldehyde and their synergistic effect against cyadox-induced cytotoxicity in rabbit erythrocytes," Drug and Chemical Toxicology, vol. 40, no. 2, pp. 196-205, 2017.

[202] J. R. Moyano-Mendez, G. Fabbrocini, D. de Stefano et al., "Enhanced antioxidant effect of trans-resveratrol: potential of binary systems with polyethylene glycol and cyclodextrin," Drug Development and Industrial Pharmacy, vol. 40, no. 10, pp. 1300-1307, 2013.

[203] X. Huang, W. Zhao, D. Hu et al., "Resveratrol efficiently improves pulmonary function via stabilizing mast cells in a rat intestinal injury model," Life Sciences, vol. 185, pp. 3037, 2017.

[204] H. Zhang, H. Yan, X. Zhou et al., "The protective effects of resveratrol against radiation-induced intestinal injury," BMC Complementary and Alternative Medicine, vol. 17, no. 1, p. 410, 2017.

[205] S. Cho, K. Namkoong, M. Shin et al., "Cardiovascular protective effects and clinical applications of resveratrol," Journal of Medicinal Food, vol. 20, no. 4, pp. 323-334, 2017.

[206] L. L. Liu, J. H. He, H. B. Xie, Y. S. Yang, J. C. Li, and Y. Zou, "Resveratrol induces antioxidant and heat shock protein mRNA expression in response to heat stress in black-boned chickens," Poultry Science, vol. 93, no. 1, pp. 54-62, 2014.

[207] S. Bo, G. Ciccone, A. Castiglione et al., "Anti-inflammatory and antioxidant effects of resveratrol in healthy smokers a randomized, double-blind, placebo-controlled, crossover trial," Current Medicinal Chemistry, vol. 20, no. 10, pp. 1323-1331, 2013.

[208] P. Farris, M. Yatskayer, N. Chen, Y. Krol, and C. Oresajo, "Evaluation of efficacy and tolerance of a nighttime topical antioxidant containing resveratrol, baicalin, and vitamin e for treatment of mild to moderately photodamaged skin," Journal of Drugs in Dermatology, vol. 13, no. 12, pp. 14671472, 2014.

[209] C. Apostolidou, K. Adamopoulos, S. Iliadis, and C. Kourtidou-Papadeli, "Alterations of antioxidant status in asymptomatic hypercholesterolemic individuals after resveratrol intake," International Journal of Food Sciences and Nutrition, vol. 67, no. 5, pp. 541-552, 2015.

[210] L. K. Mischley, K. E. Conley, E. G. Shankland et al., "Central nervous system uptake of intranasal glutathione in Parkinson's disease," NPJ Parkinson's Disease, vol. 2, no. 1, article 16002, 2016.

[211] L. K. Mischley, R. C. Lau, E. G. Shankland, T. K. Wilbur, and J. M. Padowski, "Phase IIb study of intranasal glutathione in Parkinson's disease," Journal of Parkinson's Disease, vol. 7, no. 2, pp. 289-299, 2017.

[212] B. Schmitt, M. Vicenzi, C. Garrel, and F. M. Denis, "Effects of $\mathrm{N}$-acetylcysteine, oral glutathione (GSH) and a novel sublingual form of GSH on oxidative stress markers: a comparative crossover study," Redox Biology, vol. 6, pp. 198-205, 2015. 
[213] V. Plaisance, S. Brajkovic, M. Tenenbaum et al., "Endoplasmic reticulum stress links oxidative stress to impaired pancreatic beta-cell function caused by human oxidized LDL," PLoS One, vol. 11, no. 9, article e0163046, 2016.

[214] K. Eakin, R. Baratz-Goldstein, C. G. Pick et al., "Efficacy of $\mathrm{N}$-acetyl cysteine in traumatic brain injury," PLoS One, vol. 9, no. 4, article e90617, 2014.

[215] J. Stark, "Oxidativ stressz es atherosclerosis," Orvosi Hetilap, vol. 156, no. 28, pp. 1115-1119, 2015.

[216] I. Karimzadeh, H. Khalili, S. Dashti-Khavidaki et al., " $\mathrm{N}$-acetyl cysteine in prevention of amphotericin- induced electrolytes imbalances: a randomized, double-blinded, placebo-controlled, clinical trial," European Journal of Clinical Pharmacology, vol. 70, no. 4, pp. 399-408, 2014.

[217] B. Kazemi, F. Akbarzadeh, N. Safaei, A. Yaghoubi, K. Shadvar, and K. Ghasemi, "Prophylactic high-dose oral$\mathrm{N}$-acetylcysteine does not prevent atrial fibrillation after heart surgery: a prospective double blind placebo-controlled randomized clinical trial," Pacing and Clinical Electrophysiology, vol. 36, no. 10, pp. 1211-1219, 2013.

[218] A. Karbasi, S. Hossein Hosseini, M. Shohrati, M. Amini, and B. Najafian, "Effect of oral $\mathrm{N}$-acetyl cysteine on eradication of helicobacter pylori in patients with dyspepsia," Minerva Gastroenterologica e Dietologica, vol. 59, no. 1, pp. 107-112, 2013.

[219] P. Dabirmoghaddam, A. Amali, M. Motiee Langroudi, M. R. Samavati Fard, M. Hejazi, and M. Sharifian Razavi, "The effect of N-acetyl cysteine on laryngopharyngeal reflux," Acta Medica Iranica, vol. 51, no. 11, pp. 757-764, 2013.

[220] F. L. Crane, "Biochemical functions of coenzyme Q10," Journal of the American College of Nutrition, vol. 20, no. 6, pp. 591-598, 2001.

[221] V. Mugoni, A. Camporeale, and M. M. Santoro, "Ubiad1 is an antioxidant enzyme that regulates eNOS activity by CoQ10 synthesis," Cell, vol. 152, no. 3, pp. 504-518, 2013.

[222] U. Alehagen, J. Alexander, and J. Aaseth, "Supplementation with selenium and coenzyme Q10 reduces cardiovascular mortality in elderly with low selenium status. A secondary analysis of a randomised clinical trial," PLoS One, vol. 11, no. 7, article e0157541, 2016.

[223] U. Alehagen, P. Johansson, J. Aaseth, J. Alexander, and D. Wagsater, "Significant changes in circulating microRNA by dietary supplementation of selenium and coenzyme Q10 in healthy elderly males. A subgroup analysis of a prospective randomized double-blind placebo-controlled trial among elderly Swedish citizens," PLoS One, vol. 12, no. 4, article e0174880, 2017.

[224] U. Alehagen, P. Johansson, J. Aaseth, J. Alexander, and K. Brismar, "Increase in insulin-like growth factor 1 (IGF-1) and insulin-like growth factor binding protein 1 after supplementation with selenium and coenzyme Q10. A prospective randomized double-blind placebo-controlled trial among elderly Swedish citizens," PLoS One, vol. 12, no. 6, article e0178614, 2017.

[225] N. Aslanabadi, N. Safaie, Y. Asgharzadeh et al., "The randomized clinical trial of coenzyme Q10 for the prevention of periprocedural myocardial injury following elective percutaneous coronary intervention," Cardiovascular Therapeutics, vol. 34, no. 4, pp. 254-260, 2016.

[226] J. McLachlan, E. Beattie, M. P. Murphy et al., "Combined therapeutic benefit of mitochondria-targeted antioxidant, MitoQ10, and angiotensin receptor blocker, losartan, on cardiovascular function," Journal of Hypertension, vol. 32, no. 3, pp. 555-564, 2014.

[227] B. J. Snow, F. L. Rolfe, M. M. Lockhart et al., "A double-blind, placebo-controlled study to assess the mitochondria-targeted antioxidant MitoQ as a disease-modifying therapy in Parkinson's disease," Movement Disorders, vol. 25, no. 11, pp. 16701674, 2010.

[228] H. Sies, "Ebselen, a selenoorganic compound as glutathione peroxidase mimic," Free Radical Biology \& Medicine, vol. 14, no. 3, pp. 313-323, 1993.

[229] H. Masumoto and H. Sies, "The reaction of ebselen with peroxynitrite," Chemical Research in Toxicology, vol. 9, no. 1, pp. 262-267, 1996.

[230] T. Sakurai, M. Kanayama, T. Shibata et al., "Ebselen, a selenoorganic antioxidant, as an electrophile," Chemical Research in Toxicology, vol. 19, no. 9, pp. 1196-1204, 2006.

[231] J. Kil, E. Lobarinas, C. Spankovich et al., "Safety and efficacy of ebselen for the prevention of noise-induced hearing loss: a randomised, double-blind, placebo-controlled, phase 2 trial," The Lancet, vol. 390, no. 10098, pp. 969-979, 2017.

[232] J. Mahadevan, S. Parazzoli, E. Oseid et al., "Ebselen treatment prevents islet apoptosis, maintains intranuclear Pdx-1 and MafA levels, and preserves $\beta$-cell mass and function in ZDF rats," Diabetes, vol. 62, no. 10, pp. 3582-3588, 2013.

[233] X. Wang, J. W. Yun, and X. G. Lei, "Glutathione peroxidase mimic ebselen improves glucose-stimulated insulin secretion in murine islets," Antioxidants \& Redox Signaling, vol. 20, no. 2, pp. 191-203, 2014.

[234] J. A. Beckman, A. B. Goldfine, J. A. Leopold, and M. A. Creager, "Ebselen does not improve oxidative stress and vascular function in patients with diabetes: a randomized, crossover trial," American Journal of Physiology-Heart and Circulatory Physiology, vol. 311, no. 6, pp. H1431H1436, 2016.

[235] N. V. Barbosa, C. W. Nogueira, P. A. Nogara, A. F. de Bem, M. Aschner, and J. B. T. Rocha, "Organoselenium compounds as mimics of selenoproteins and thiol modifier agents," Metallomics, vol. 9, no. 12, pp. 1703-1734, 2017.

[236] K. Kikuchi, S. Tancharoen, N. Takeshige et al., "The efficacy of edaravone (radicut), a free radical scavenger, for cardiovascular disease," International Journal of Molecular Sciences, vol. 14, no. 7, pp. 13909-13930, 2013.

[237] J. D. Rothstein, "Edaravone: a new drug approved for ALS," Cell, vol. 171, no. 4, p. 725, 2017.

[238] D. Rischin, R. J. Hicks, R. Fisher et al., "Prognostic significance of [18F]-misonidazole positron emission tomographydetected tumor hypoxia in patients with advanced head and neck cancer randomly assigned to chemoradiation with or without tirapazamine: a substudy of trans-tasman radiation oncology group study 98.02," Journal of Clinical Oncology, vol. 24, no. 13, pp. 2098-2104, 2006.

[239] D. Rischin, L. J. Peters, B. O'Sullivan et al., “Tirapazamine, cisplatin, and radiation versus cisplatin and radiation for advanced squamous cell carcinoma of the head and neck (TROG 02.02, HeadSTART): a phase III trial of the transtasman radiation oncology group," Journal of Clinical Oncology, vol. 28, no. 18, pp. 2989-2995, 2010. 


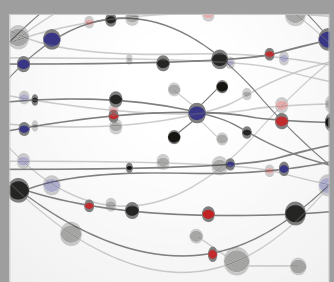

The Scientific World Journal
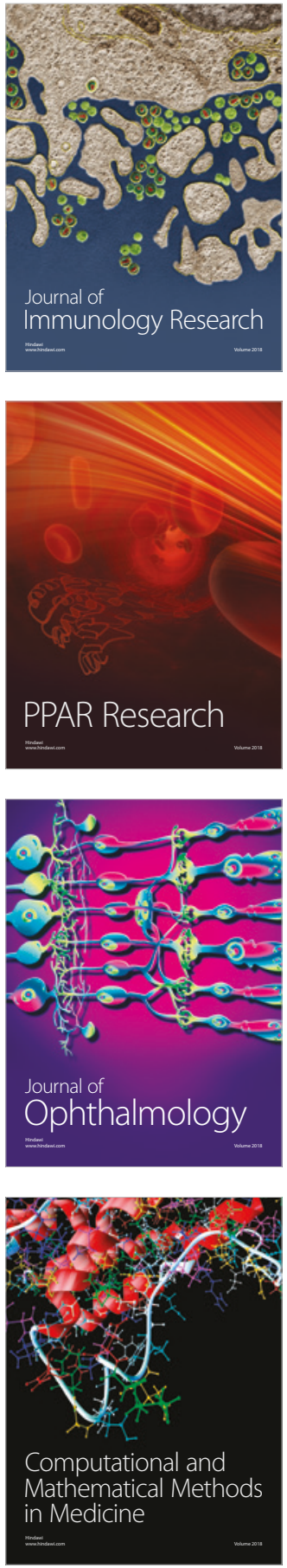

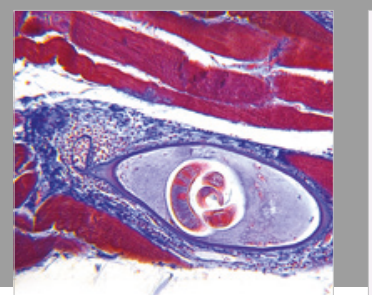

Gastroenterology Research and Practice

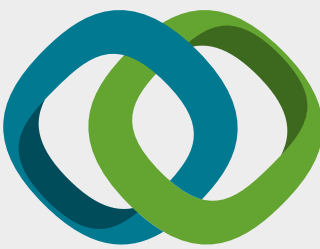

\section{Hindawi}

Submit your manuscripts at

www.hindawi.com
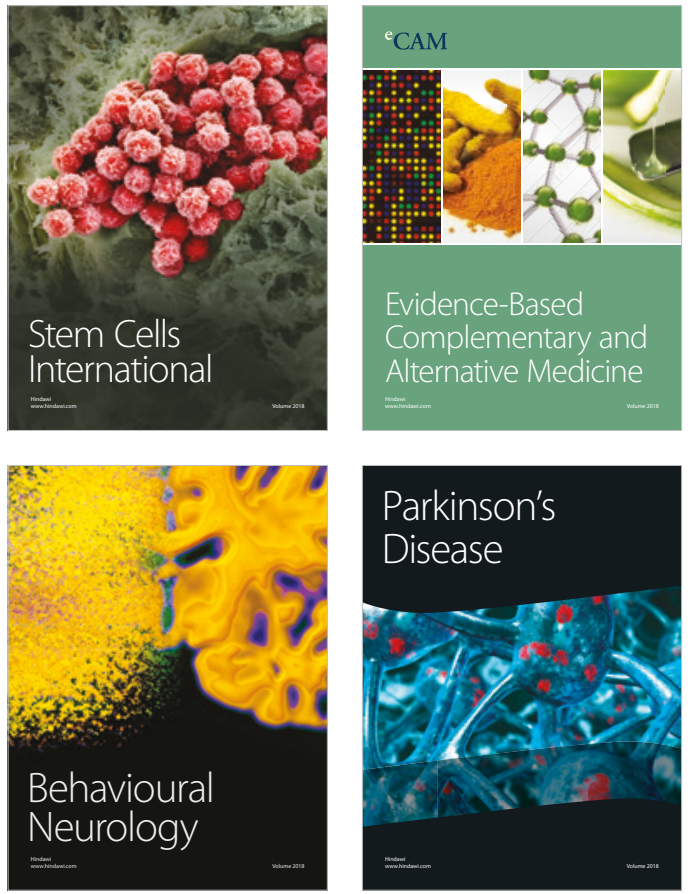

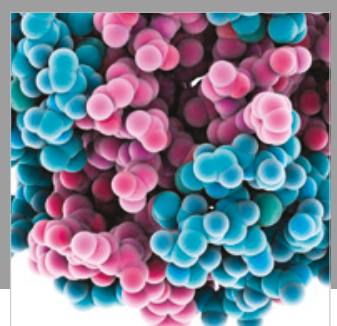

ournal of

Diabetes Research

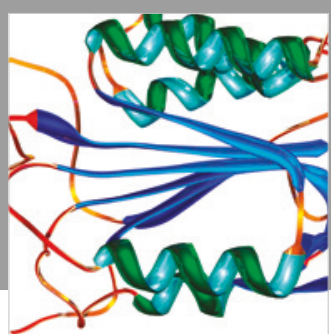

Disease Markers
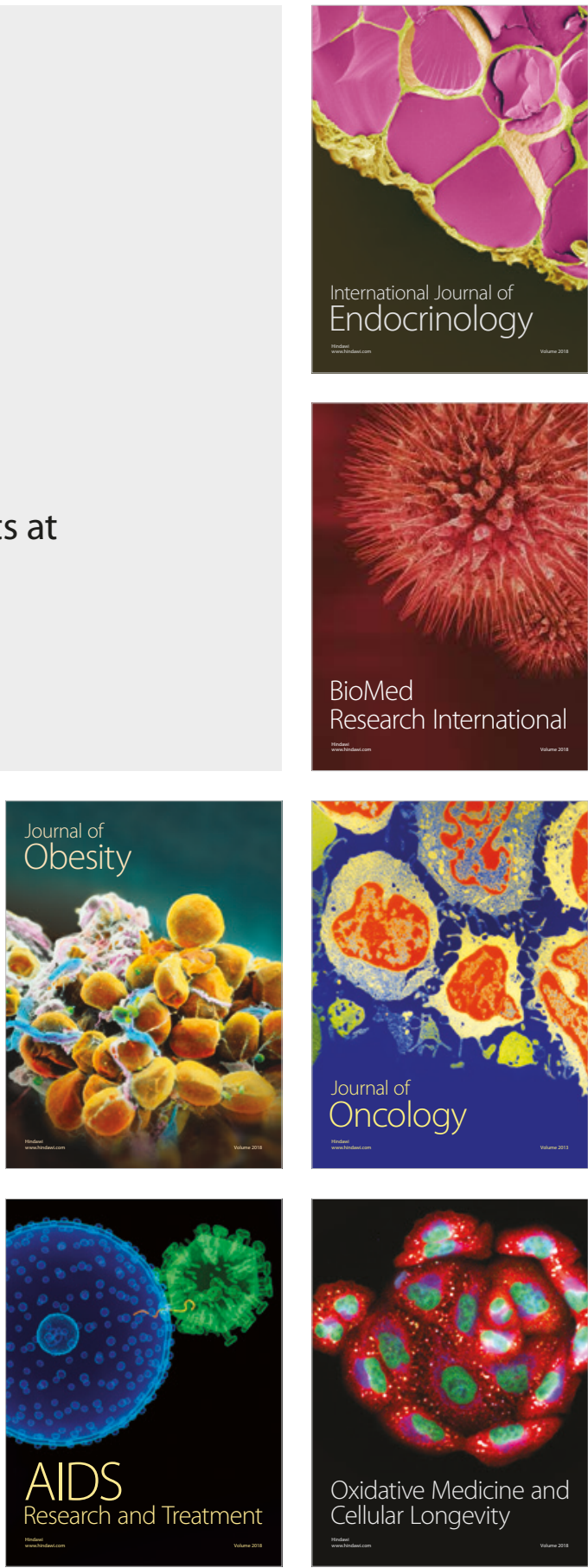